\title{
3-D analysis of fatigue crack behaviour in a shot peened steam turbine blade material
}

\author{
B.Y. He ${ }^{1, *}$, O.L. Katsamenis ${ }^{2}$, B.G. Mellor ${ }^{1}$, P.A.S. Reed ${ }^{1}$ \\ ${ }^{1}$ Engineering Materials, Faculty of Engineering and the Environment, \\ University of Southampton, Highfield, Southampton, SO17 1BJ, UK \\ ${ }^{2} \mu$ VIS X-ray Imaging Centre, Faculty of Engineering and the Environment, \\ University of Southampton, SO17 1BJ, Southampton, UK \\ * Corresponding author. Tel.: +44 2380 599450; fax: +44 2380593016. \\ E-mail address: Binyan.he@soton.ac.uk (B.Y.He)
}

\begin{abstract}
Serial mechanical sectioning and high resolution X-ray tomography have been used to study the three-dimensional morphology of small fatigue cracks growing in a $12 \mathrm{Cr}$ tempered martensitic steam turbine blade material. A range of surface conditions has been studied, namely polished and shot peened (with varying levels of intensity). In the polished (unpeened) condition, inclusions (alumina and manganese sulphide) played an important role in initiating and controlling early fatigue crack behaviour. When fatigue cracks initiated from an alumina stringer, the crack morphology was normally dominated by single stringers, which were always in the centre of the fatigue crack, indicating its primary role in initiation. Manganese sulphide inclusion groups however seemed to dominate and affect the crack path along both the surface and depth crack growth directions. The more intensely shot peened condition did not however evidence inclusion or stringer affected fatigue crack initiation or growth behaviour; sub-surface crack coalescence being clearly observed by both serial sectioning and CT (computed tomography) imaging techniques at a depth of about $150 \sim 180 \mu \mathrm{m}$. These sub-surface crack coalescences can be linked to both the extent of the compressive residual stress as well as the depth of the plastic deformation arising from the intense shot peening process. Shot peening appears to provide a different defect population that initiates fatigue cracks and competes with the underlying metallurgical defect populations. The most beneficial shot peening process would in this case appear to "deactivate"
\end{abstract}


the original metallurgical defect population and substitute a known defect distribution from the shot peening process from which fatigue cracks grow rather slowly in the strain hardened surface layer which also contains compressive residual stresses. A benefit to fatigue life in bending, even under Low Cycle Fatigue (LCF) conditions, has been observed in these tests if a sufficiently severe shot peening condition is applied in a constrained notch configuration.

Key words: low cycle fatigue (LCF); shot peening; residual stress and strain hardening; 3 dimension (3D) small crack morphology; serial sectioning; X-ray micro-computed tomography (X-ray $\mu$-CT)

\section{Introduction}

Fatigue is a particular concern in many engineering components and there are two conventional approaches used in many studies to evaluate fatigue crack growth behaviour. The D.C. (direct current) potential drop (P.D.) method is often used to monitor long fatigue crack propagation from a pre-existing defect (usually a sharp notch) [1]. Crack growth can be monitored continuously using this technique, but the calibration of the P.D. evolution and the link to averaged crack growth behaviour must be based on a known crack geometry (which is usually checked post-test). In the case of short (or naturally initiating) fatigue cracks, when the site of initiation is not known before the test, surface replication methods are quite common. The replication technique reproduces the surface features via a softened acetate block or silicone compound which is applied at intervals during the fatigue process to the possible crack initiating region or a stress concentration zone on a specimen or component surface, thus providing a series of snapshots of the crack growth process on the surface. However, the growth of a small fatigue crack is a complex $3 \mathrm{D}$ process, especially for surface breaking or sub-surface initiating short cracks which typically have a more complex 3D crack shape than conventional through thickness long cracks. In this case the 3D interaction with other features such as local microstructure [2], residual stress[3], inclusions or second phases [4, 5], can significantly affect initiation and propagation behaviour during fatigue since the stress (or strain) intensity distribution around the crack periphery changes. In addition simple measures of fatigue crack growth, $d a / d N$, are based on underlying assumptions of a single crack with a crack driving force that can be described simply (e.g. by a single $\Delta K$ value). This is often not adequate to 
characterize the actual fatigue crack behaviour (for example, crack coalescence). The three dimensional fatigue crack shape also provides a better reflection of true fatigue crack behaviour and needs to be taken into account in any detailed quantitative fatigue crack behaviour analysis [6].

The experimental techniques used to reveal 3D shapes can generally be categorized into two classes, namely destructive and non-destructive techniques. Heat tinting [7, 8] and mechanical serial sectioning [9-11] are examples of conventional 3D reconstruction approaches. In recent years, substantial improvements in material characterization techniques, and the combination of focussed ion beam (FIB), SEM or electron back scattered diffraction (EBSD) [12-15] has enabled 3D reconstruction of microstructures or the interaction between microstructure and fatigue cracks with a resolution down to a few micrometres[16]. As a non-destructive technique, X-ray computed tomography (either with a lab source or a synchrotron X-ray source) is an attractive technique, capable of achieving spatial resolution in the sub-micron range $(\sim 700 \mathrm{~nm})$, and in the case of nano-CT even smaller. Acquisition time ranges from several minutes to several days, depending on a multitude of factors; e.g. source intensity, the sample material, the desired resolution, etc. [17-19]. Initially, the X-ray tomography technique was developed for medical applications [20] and it was not until early 2000 that CT started to be used for characterisation in materials science[21]. Recently CT and $\mu-\mathrm{CT}$ have been increasingly used within materials science to visualize the microstructure in $3 \mathrm{D}$ [22], the interaction of microstructure and fatigue cracks [23-27] etc. It can provide important qualitative (or even quantitative) evaluation of a 3D microstructure and its interaction with crack morphologies by static or in-situ CT-imaging $[25,28]$. The combination of X-ray tomography and electron back scatter diffraction (EBSD) is able to provide extra information about, for example, the relation between the crystallographic orientation of individual grains and subsequent crack path, allowing the prediction of preferred crack orientation [29]; similarly, the recently developed X-ray diffraction contrast tomography can characterize grain orientation in polycrystalline materials in $3 \mathrm{D}$, and a fuller description needed to analyse local crack growth rates of short fatigue cracks in three dimensions can also be obtained by combining it with propagation-based phase contrast tomography [30]. However, $\mu$-CT imaging of steel can be challenging especially when sub-micrometer pixel resolution is required. The main challenge arises from the fact that, for a given photon energy, the X-ray linear attenuation coefficient, $\mu$, of a material is dependent on 
the atomic number, $Z$, of its constituent elements as well as its geometrical characteristics. Higher $Z$ leads to higher attenuation. In the case of steel, the determinant element is $\mathrm{Fe}\left(\mathrm{Z}_{\mathrm{Fe}}=55.8\right)$, which, for the relatively low photon energies that high-resolution $\mu$-CT scanners use nowadays, means that, even when miniature samples are employed, only a small proportion of the generated photons will be able to get through the sample and interact with the detector. To compensate for this, long exposures have to be utilised and as a result a scanning time of tens of hours is not uncommon.

Shot peening is a well-known method to improve fatigue properties of stress concentration features. Extensive efforts have been made to study the influence of shot peening induced factors in the near-surface (surface roughness, compressive residual stress regions as well as the plastic strain layer) in both high cycle fatigue (HCF) and low cycle fatigue (LCF) regimes in different material systems (such as steel [31, 32], Al alloys [3, 33] etc.). However, most of these studies which have focused on the effect of shot peening on fatigue crack initiation and propagation behaviour or the effect of stress relaxation, were generally confined to surface observations which provide no information about the three-dimensional (3D) shape of these cracks. Although Mutoh's research indicated that the fatigue crack morphologies varied significantly in shot peened and unpeened layers [3], there seems to be little detailed information available in the literature on how the $3 \mathrm{D}$ surface breaking fatigue crack morphologies are affected by the shot peened layers. Understanding this will provide important information on the evolution of the crack growth and will lead to more quantitative and micromechanically informed shot peening fatigue life assessments.

The present study is part of a larger project detailed in [31, 34-36], focussed on understanding the effects of shot peening on fatigue crack initiation and propagation behaviour in steam turbine blade materials in the LCF regime. Both mechanical serial sectioning and X-ray tomography (using a lab source) were used to study in detail the 3D fatigue crack morphology under these shot peened conditions, and this paper focuses on these investigations.

\section{Materials and Experimental Method}

A full description of the fatigue sample and experiment details have been provided in previous publications [31, 34-36] and the relevant details are reported here only briefly. The material in this study is a steam turbine blade 
material, FV448, a ferritic heat resistant steel with a tempered martensitic microstructure. The composition of the steel evaluated in the present work is Fe-0.12 C-0.94 Mn-0.31 Si-0.74 Ni-11.0 Cr-0.58 Mo-0.31 V-0.34 Nb (wt \%) [31]. This barstock material had been austenitised at $1150{ }^{\circ} \mathrm{C}$, oil quenched, and then tempered at $650{ }^{\circ} \mathrm{C}$ [37]. Stringers were found on the L-T and L-S planes within the FV448 matrix; the position of the stringers in the barstock is shown in the schematic illustration in Figure 1(a). Figure 1(a) and (b) show inclusions of aluminium oxide/silicate and manganese sulphide aligned in the L-T and L-S plane, respectively. The fatigue sample contains a "U-notch" which results in a stress concentration factor of 1.6, to simulate the fir tree geometry in steam turbine blade components. Fatigue testing was carried out in three point bending at a frequency of $20 \mathrm{~Hz}$ using a sinusoidal waveform and a load ratio $\mathrm{R}=0.1$, using an Instron 8502 servo hydraulic machine at ambient temperature. Three surface conditions were studied, as listed in Table 1. For the baseline condition, the surface was polished down to $1 \mu \mathrm{m}$, while for the $\mathrm{T} 0$ and $\mathrm{T} 1$ shot peened conditions, the surface roughness $\mathrm{Ra}$ is 3.6 and $1.25 \mu \mathrm{m}$, respectively. All these samples were subjected to similar strain range conditions $\left(\Delta \varepsilon_{11}=0.68 \%\right)$, during the fatigue tests and the fatigue process was interrupted and the specimens removed from the fatigue test apparatus at $70 \sim 80 \%$ of the fatigue life based on the $\mathrm{S} / \mathrm{N}$ curves determined in a previous study [31]. The $3 \mathrm{D}$ crack morphologies resulting from testing polished and T0 shot peened samples were studied by serial mechanical sectioning, while a laboratory based X-ray CT imaging approach was employed for both the $\mathrm{T} 0$ and $\mathrm{T} 1$ shot peened cases.

\subsection{Serial Mechanical Sectioning}

In order to assess how the shot peening process affected the fatigue crack morphology, the polished surface condition (in the plain bend bar sample) has been compared with the T0 shot peening condition (U-notch sample) in the serial mechanical sectioning investigation. For the polished sample, the serial sectioning process was conducted using the Struers Tegraplo-15; the polishing conditions were: 5 minutes for $3 \mu \mathrm{m}$ lubricant and another 5 minutes for $1 \mu \mathrm{m}$ lubricant under a $20 \mathrm{~N}$ force. For the T0 condition, the material removal was carried out in the specimen notch root using a column pillar drilling machine holding a metal rod to which abrasive paper of 1200 and 4000 grits was attached. Grinding times of 3 and 5 minutes were used for the 1200 and 4000 papers, respectively; this was followed by polishing with dental felt impregnated with 3 and then $1 \mu \mathrm{m}$ lubricant for another 5 minutes. Around 
$5 \mu \mathrm{m}$ of material was removed during each polishing step; the schematic showing the polishing direction is presented in Figure 2(a). In order to reveal fatigue cracks, especially in the layers further from the surface where cracks were not open, diluted Vilella's regent (Picric Acid 1 g, Hydrochloric acid $5 \mathrm{ml}$, Ethanol $100 \mathrm{ml}$, diluted with $50-100 \mathrm{ml}$ distilled water) was applied to the polished surface to highlight the crack paths. Micro-hardness indents were utilised as fiduciary markers around the cracks to assess the depth of material removal at various points. The initial (and subsequent) depth of the indent can be assessed from its diagonal length: for a Vickers diamond pyramid indenter (a square pyramid with opposite faces at an angle of $136^{\circ}$ and edges at $2 \psi=148^{\circ}$ ), the depth of the indent is $1 / 7$ of the indent diagonal $d$. In the present research, a $1000 \mathrm{~g}$ load with a 15 second dwell time was chosen; five to six indents positioned to avoid the fatigue crack paths were made across the notch root region. After polishing, images of the full notch root region were taken by optical microscopy, which provided a record of crack morphologies and allowed the measurements of the diagonals of each indent; the depth of the material removed was then calculated based on the averaged diagonal change of all the indents. In order to retain crack detail as much as possible, the removal of material for each step was controlled to be less than $\sim 5 \mu \mathrm{m}$. The sequence of indentations, grinding and subsequent imaging was continued until the full depth of the fatigue $\operatorname{crack}(\mathrm{s})$ had been established. 134 and 224 steps of the material removal process were carried out for the initial polished surface and T0 shot peened conditions respectively, corresponding to a total layer removed of 384 and $688 \mu \mathrm{m}$, respectively. This allowed a series of 2D images of the fatigue crack along the depth direction to be obtained. All the 2D images were stacked together in the polishing direction by Photoshop aided by the indent positions in each slice. Avizo Fire 7.0 was used to process these stacked 2D images. In addition, special care was taken to make sure that the distance between each $2 \mathrm{D}$ slice inputted into Avizo was exactly the same as that removed during each polishing step.

\subsection{X-ray Computed Tomography}

The cracks produced in the U-notched $\mathrm{T} 1$ (low intensity) and T0 (high intensity) shot peened surface conditions were chosen to be further studied by means of micro- X-ray computed tomography $(\mu-\mathrm{CT})$ on the 'ZEISS Xradia 510 Versa 3D X-ray microscope' at the $\mu$-VIS X-ray imaging centre at the University of Southampton. Due to the high degree of attenuation of X-rays in steel, a 'match 
stick'-like sample (dimensions $\sim 2 \times 2 \times 8 \mathrm{~mm}$ ) was cut out from the notch root of the specimens (cf. Figure 2(b)) so that a minimum of $10 \%$ transmission of the incoming X-ray beam was preserved at all exposure angles.

The scan of $\mathrm{T} 1$ was conducted at a peak voltage of $150 \mathrm{kV}$ and the beam was pre-filtered through $2.5 \mathrm{~mm}$ of $\mathrm{CaF}_{2}$ to reduce beam-hardening artefacts. To achieve sufficient flux, the power was set at $10 \mathrm{~W}(67 \mu \mathrm{A})$ and the $2026 \times 2026$ detector was binned twice resulting in effective detector dimensions of 1012x1012. The source to detector distance was set at $93.4 \mathrm{~mm}$ (SrcZ: -16.7 , DetZ: +76.6), which in combination with the $4 \mathrm{x}$ lens resulted in a pixel size of $1.2 \mu \mathrm{m}$; i.e. a spatial resolution of approximately $3 \mu \mathrm{m}$. During the tomogram, a total of 3201 radiographs were collected with an angular step of $\sim 0.11^{\circ}$ over a 360 degree rotation of the sample.

Due to small size variations between $\mathrm{T} 1$ and $\mathrm{T} 0$ samples, $\mathrm{T} 0$ was scanned with slightly different parameters. A total of 2001 radiographs were collected with an angular step of $\sim 0.18^{\circ}$, the detector was not binned and the source to detector distance was $137.8 \mathrm{~mm}(\mathrm{SrcZ}:-36.1$, DetZ: +101.7$)$ resulting in a pixel size of $0.88 \mu \mathrm{m}$. All other parameters remained unchanged.

In order to capture the damaged area located at the root of the notch, and given that at the aforementioned pixel conditions the imaging volume ranges from $\sim 1$ $-1.5 \mathrm{~mm}^{3}$, local tomography scans had to be performed (note: local tomography is defined as the acquisition mode during which only a selected region of the sample is imaged with the rest of the sample going outside the field of view during the rotation). The specimens were positioned such that the surface of their notch-root remained within the field of view during the full $360^{\circ}$ rotation.

Prior to each scan, a fast (60 min) warm-up scan was performed in order to ensure that thermal equilibrium had been reached within the X-Ray source and the scanner enclosure. Following the acquisition, the raw data were reconstructed using Zeiss' reconstruction software, which uses a filtered back projection algorithm.

\section{Results}

\subsection{Three dimensional crack morphology revealed by serial sectioning}

To simplify description in the present study, cracks which appeared on polished samples on the mechanically prepared serial sections will be identified as $\mathrm{P}_{\mathrm{s}}-1$, $\mathrm{P}_{\mathrm{s}}-2, \ldots$; similarly, cracks on the T0 shot peened sample are designated $\mathrm{SP}_{\mathrm{s}^{-}}-1$, 
$\mathrm{SP}_{\mathrm{s}}-2$, where "P" and "SP" indicate the "polished" and "shot peened" condition, respectively, " 0 " means the "T0" process, and the subscript "s" represents serial sectioning. Figure 3 shows crack $\mathrm{P}_{\mathrm{s}}-1$ (from the baseline polished sample) at different depths, and thus presents the evolution of crack morphology in the polishing direction (the $\mathrm{z}$ direction). For both crack $\mathrm{P}_{\mathrm{s}}-1$ (a) and $\mathrm{P}_{\mathrm{s}}-1(\mathrm{~b})$, the crack paths seem to be related to the positions of manganese sulphide, MnS, inclusions. The distribution of these inclusions on the crack path indicated that they were the crack initiators. Figure 4 shows the 3D fatigue crack reconstruction based on the $2 \mathrm{D}$ images of crack $\mathrm{P}_{\mathrm{s}}-1$ (a) and $\mathrm{P}_{\mathrm{s}}-1(\mathrm{~b})$. The crack discontinuities in the $\mathrm{z}$ direction are due to the finite number of serial sectioning steps but the general 3D crack morphology can still be ascertained. The crack region and inclusions are indicated as blue and red in crack $\mathrm{P}_{\mathrm{s}}-1(\mathrm{a})$, and green and orange in crack $\mathrm{P}_{\mathrm{s}}-1(\mathrm{~b})$, respectively. The $\mathrm{MnS}$ stringers are discontinuous in the $z$ direction (the rolling direction), which also agrees with observations on a fatigue sample after an interrupted fatigue test when, following heat tinting, the crack was broken open and the fracture surface observed [35]. Due to the effect of the inclusions, crack $\mathrm{P}_{\mathrm{s}}-1$ (a) and crack $\mathrm{P}_{\mathrm{s}}-1$ (b) are very tortuous in terms of both $2 \mathrm{D}$ and $3 \mathrm{D}$ morphology.

The crack grouping $\mathrm{P}_{\mathrm{s}}-2$ is from the same sample but a different crack; the effect of $\mathrm{MnS}$ on the fatigue crack morphology can be appreciated from Figure 5 and Figure 6. The green and red regions represent crack regions, while the blue regions are $\mathrm{MnS}$ stringers. $\mathrm{P}_{\mathrm{s}}-2$ appears to be a single crack, judging from the serial $2 \mathrm{D}$ sections, when the material removal was less than $120 \mu \mathrm{m}$ from the notch root; however, this single crack became two different cracks at a depth of $\sim 126 \mu \mathrm{m}$. These two separate cracks were more apparent at a depth of $136.5 \mu \mathrm{m}$. Three cracks, clearly initiating from inclusions, were found at $\sim 235 \mu \mathrm{m}$ below the notch root. It seems that the inclusions (MnS) dominate the crack path, in both surface and depth crack growth directions. However, for crack $\mathrm{P}_{\mathrm{s}}-3$, only one single stringer (Alumina) dominates the crack morphology; the $2 \mathrm{D}$ crack images at various depths and the $3 \mathrm{D}$ crack reconstruction are shown in Figure 7 and Figure 8, respectively. The stringer is in the central part of the crack region, and seems to be the crack initiator. This is also consistent with cracks observed in heat tinted and subsequently broken open interrupted fatigue test samples reported in [35]. Crack $\mathrm{P}_{\mathrm{s}}-3$ is less tortuous than both cracks $\mathrm{P}_{\mathrm{s}}-1$ and crack $\mathrm{P}_{\mathrm{s}}-2$, as the alumina stringer is the dominant crack initiator. 
Figure 9 shows the 2D images of crack $\mathrm{SP}_{\mathrm{s}}-1$ at selected depths in the T0 shot peening condition and the 3D crack reconstruction is presented in Figure 10. Crack $\mathrm{SPO}_{\mathrm{s}}-1$ is actually formed from 5 different cracks, denoted as cracks $\mathrm{SP}_{\mathrm{s}}-1(\mathrm{a}), \mathrm{SP}_{\mathrm{s}^{-}}-1(\mathrm{~b}), \mathrm{SP}_{\mathrm{s}}-1(\mathrm{c}), \mathrm{SP}_{\mathrm{s}}-1(\mathrm{~d}), \mathrm{SP}_{\mathrm{s}}-1(\mathrm{e})$. These five cracks appear to be individual cracks when observed via the conventional replication technique applied to the shot peened surface. The surface crack lengths of these cracks are 347, 415, 385, 181 and $341 \mu \mathrm{m}$ respectively. However, as the shot peened layer was polished off, at $0.76 \mu \mathrm{m}$ beneath surface, crack tips were more clearly identified and when the polishing depth was $36 \mu \mathrm{m}$, the crack tips of $\mathrm{SP}_{\mathrm{s}}-1$ (a) and $\mathrm{SP}_{\mathrm{s}}-1$ (b) actually interacted with each other - the tendency to coalescence was apparent. From a depth of around $192 \mu \mathrm{m}$, crack SP0 $\mathrm{s}_{\mathrm{s}}-1$ (a) and $\mathrm{SP}_{\mathrm{s}}-1$ (b) had coalesced completely and at $\sim 220 \mu \mathrm{m}$ beneath the surface, crack $\mathrm{SP}_{\mathrm{s}}-1$ (a) $\mathrm{SP}_{\mathrm{s}}-1(\mathrm{~b}), \mathrm{SP}_{\mathrm{s}}-1$ (c), became a single crack, denoted as crack $\mathrm{SP}_{\mathrm{s}^{-}}$ $1(\mathrm{abc})$. It is noteworthy that the crack tips of cracks $\mathrm{SP}_{\mathrm{s}}-1(\mathrm{c})$ and $\mathrm{SP}_{\mathrm{s}}-1(\mathrm{~d})$, cracks $\mathrm{SP}_{\mathrm{s}}-1(\mathrm{~d})$ and $\mathrm{SP}_{\mathrm{s}}(\mathrm{e})$ are starting to interact with each other, as indicated in Figure 9, but these interactions have just started at the point when the fatigue process was interrupted.

In the present study, observation of sub-surface coalescence for the crack system $\mathrm{SP}_{\mathrm{s}}-1(\mathrm{abc})$ is not the only example found in the T0 shot peened condition. Figure 11 shows the $2 \mathrm{D}$ section images of crack $\mathrm{SP}_{\mathrm{s}}-2$, where subsurface crack coalescence was also identified. Initially, crack $\mathrm{SP}_{\mathrm{s}}-2$ was actually two individual cracks on the shot peened surface, labelled as cracks $\mathrm{SP}_{\mathrm{s}}-2$ (a) and $\mathrm{SP}_{\mathrm{s}}-2(\mathrm{~b})$, respectively; after $0.76 \mu \mathrm{m}$ of material was polished off, the crack morphology as well as the shot peened surface roughness was more clearly revealed. Complete crack coalescence occurred at a depth between $150 \sim 160 \mu \mathrm{m}$. As the polishing process continued, the crack shape became more tortuous, which might indicate the point at which the microstructure is affecting crack growth. For example, at $\sim 600 \mu \mathrm{m}$ beneath the shot peened surface, the crack morphology was quite tortuous, as can be seen in both the $2 \mathrm{D}$ image slices (Figure 11) and the 3D reconstruction crack morphology (Figure 12). Compared to the cracks observed in the baseline test condition, the crack shapes in the shot peened condition are less tortuous and less inclusion or stringerdominated.

\subsection{Three Dimensional Crack Morphology by Computed Tomography}

Due to the intrinsic limitation of the tomography technique, high spatial resolution depends on various factors especially the thickness of the sample, 
which has to be as thin as possible to avoid lateral spreading of the signal when a photon impinging on the screen is turned into visible light [38]. Therefore, the volume under investigation in the present study had to be limited for both the $\mathrm{T} 1$ and $\mathrm{T} 0$ shot peened conditions. In a similar manner to before, cracks in the $\mathrm{T} 0$ and $\mathrm{T} 1$ shot peened condition will be designated $\mathrm{SP}_{\mathrm{x}}-1, \mathrm{SP}_{\mathrm{x}}-2, \ldots$, and $\mathrm{SP} 1_{\mathrm{x}}-1, \mathrm{SP} 1_{\mathrm{x}}-2$, where "SP" represents shot peened condition, " 0 " and " 1 " indicated $\mathrm{T} 0$ and $\mathrm{T} 1$ process, respectively, and the subscript " $\mathrm{x}$ " represents $\mathrm{X}$ ray computed tomography imaging. Crack morphologies obtained by X-ray tomography in the $\mathrm{T} 1$ shot peened condition are presented in Figure 13. The crack loading directions (the tensile axis) are indicated by the arrows. T1 shot peening was a less intense process, and the dimples induced on the sample surface were not as obvious in the cross sectional view of the notch geometry; the shot peened dimples are very shallow, as indicated in Figure 13 (a). The stringers overlap with the fatigue crack, labelled as crack $\mathrm{SP} 1_{\mathrm{x}}-1$, so for the lighter shot peening condition (T1), inclusions actually acted as the crack initiation sites (as observed in the polished baseline case). This agrees with previous results which showed that the fatigue crack initiation and propagation behaviour under the less intense shot peened condition exhibits features of both the unpeened and more intense shot peened cases [35]. Figure 13(b)-(f) illustrate how the crack morphology changes at different depths $(d=20,43,112$, 203, $417 \mu \mathrm{m})$. The inclusions are clear at this series of different depths. To visualize the fatigue crack morphology, the $3 \mathrm{D}$ crack reconstruction is presented in Figure 14. The fatigue crack has been highlighted in blue while the inclusion is red. Generally, the crack shape was somewhat discontinuous, and the crack tips were also irregular. The discontinuous nature of the fatigue crack can be partly explained by resolution issues and possible partial closure of the crack as well as the expected fatigue crack behaviour; the nature of the crack was similar to the crack morphology revealed on the fracture surfaces in previous heattinting and fractured interrupted fatigue tests [35]. However, it is still apparent that this is a semi-elliptical crack and one of the inclusions is clearly located in the crack centre region. In addition, another two inclusions were also found in the volume studied but they did not seem to affect the fatigue crack shape, as the effects of shot peening dominate crack behaviour.

The fatigue cracks studied by X-ray tomography in the T0 shot peened condition had undergone 34550 fatigue cycles $(65-75 \%$ of the established fatigue life). Figure 15(a) presents a single $\mathrm{XY}$ slice of the cross section of fatigue crack $\mathrm{SP}_{\mathrm{x}}-1(\mathrm{a})$ and $\mathrm{SP}_{\mathrm{x}}-1(\mathrm{~b})$ in the $\mathrm{T} 0$ shot peened condition, where 
the relation between crack path and tensile axis (TA) is clearly illustrated. The rough geometry of the shot peened surface is quite clear: Figure 15 (a) shows, the shot peened dimples are larger than those observed in the less intense shot peened condition $\mathrm{T} 1$ (in Figure 13(a)). Interestingly, crack $\mathrm{SP}_{\mathrm{x}}-1$ (a) and crack $\mathrm{SP}_{\mathrm{x}}-1(\mathrm{~b})$ were two separate cracks in the cross section view; when the depth from the shot peened surface reached $\sim 200 \mu \mathrm{m}$, a clear tendency for these cracks to join was noted. Figure 15(b)-(f) illustrate how the fatigue crack morphologies in the $\mathrm{T} 0$ shot peened condition change along the depth direction ( $\mathrm{z}$ direction). To simplify the discussion, the fatigue cracks recognized on the top surface were identified as fatigue crack $\mathrm{SP}_{\mathrm{x}}-1(\mathrm{a}), \mathrm{SP}_{\mathrm{x}}-1(\mathrm{~b}), \mathrm{SP}_{\mathrm{x}}-1(\mathrm{c})$, respectively. At $9 \mu \mathrm{m}$ beneath the shot peened surface, these three fatigue cracks were clearly separated; as the depth increased, there was a sign that the crack tips of $\mathrm{SP}_{\mathrm{x}}-1(\mathrm{a})$ and $\mathrm{SP}_{\mathrm{x}}-1$ (b) moved toward each other gradually. At a depth of $173 \mu \mathrm{m}$, crack $\mathrm{SP}_{\mathrm{x}}-1(\mathrm{a})$ and $\mathrm{SP}_{\mathrm{x}}-1(\mathrm{~b})$ coalesced and the crack morphology at a depth of $277 \mu \mathrm{m}$ made this phenomenon more apparent. Although there was an indication that the crack tips of $\mathrm{SP}_{\mathrm{x}}-1(\mathrm{~b})$ and $\mathrm{SP}_{\mathrm{x}}-1(\mathrm{c})$ also tried to coalesce sub-surface (at around $180 \mu \mathrm{m}$ beneath the surface), there is insufficient evidence due to the resolution issue as well as the noise ahead of the crack tips. Therefore, definite conclusions about the sub-surface crack coalescence of cracks $\mathrm{SP}_{\mathrm{x}}-1(\mathrm{~b})$ and $\mathrm{SP}_{\mathrm{x}}-1$ (c) cannot be drawn. However, the sub-surface crack coalescence captured for crack $\mathrm{SP}_{\mathrm{x}}-1$ (a) and crack $\mathrm{SP}_{\mathrm{x}}-1$ (b) agrees well with the results from the serial sectioning examination. In Figure 15(f), an inclusion was found about $160 \mu \mathrm{m}$ away from the fatigue crack path on the top surface view. The corresponding cross section view is shown in Figure 15(g). Although the inclusion stringer seemed close to the fatigue crack path, it did not actually interact with the cracks, indicating that the inclusion has little effect on the fatigue crack behaviour/shape in the T0 shot peened condition. 3D reconstruction of the fatigue cracks and inclusions in the T0 shot peened condition are presented in Figure 16 at different angles of view. The reason why the $3 \mathrm{D}$ crack shapes here are not typically semi-elliptical is because only the crack tip regions have been scanned due to the requirement for a small match stick extraction. However, sub-surface crack coalescence has again been captured in the T0 shot peened case.

\section{Discussion}

Previous research has focused on observations of the behaviour of fatigue cracks in the same $4.5 \times 1.25$ notch geometry samples for different surface 
conditions (polished, ground, a light intensity shot peening process $\mathrm{T} 1$ as well as the industry applied shot peened process T0) obtained by using a conventional approach namely the interrupted surface replication technique carried out at intervals throughout a fatigue test [35]. It is not the aim of the present paper to describe in detail the behaviour of the fatigue crack in both the surface and depth directions observed by this method which can be found in [35], however, in what follows, some important features are briefly restated to allow further discussion of the effect of shot peening on fatigue behaviour.

Figure 17 (a) describes the surface crack length $2 c$ at different fatigue cycles. Under similar applied strain range conditions, the fatigue lives of the polished and $\mathrm{T} 1$ cases are quite similar, both around 25000 cycles while the T0 case shows significant benefit from the shot peening process (almost twice the lifetime of the previous two cases) even in the low cycle fatigue regime. In the polished condition where the surface was finish polished with $1 \mu \mathrm{m}$ diamond paste, fatigue cracks are not likely to be affected by surface roughness. Fatigue cracks were recognized at $\sim 50 \%$ of fatigue life and these cracks propagated at a relatively constant rate (along the surface) and accelerated near the end of fatigue life. For the less intense shot peened case, fatigue cracks were also picked up clearly at $\sim 50 \%$ of fatigue life, but crack coalescence was more obvious compared to the baseline polished condition. However, in the more intensely (T0) shot peened process, some of the fatigue cracks were observed at the very early stages of fatigue life. For example, one of the initiating cracks was $51 \mu \mathrm{m}$ long, while the other one was $242 \mu \mathrm{m}$ before any cyclic loading had been applied. It seemed that these cracks pre-existed on this intensely shot peened surface and these pre-initiated cracks started to grow, albeit very slowly, at around $0.1 \sim 0.2$ of fatigue life but the crack lengths did not start to increase dramatically until $0.7 \sim 0.8$ of fatigue life, where frequent crack coalescence occurred and secondary cracks also started to propagate quickly.

A Linear Elastic Fracture Mechanics (LEFM) calculation of $K$-equilibrium around the crack front was conducted based on Scott and Thorpe's review paper [39] and the fatigue crack propagation rate $d a / d N$ is plotted against stress intensity factor range $\Delta K_{\text {depth }}$ in Figure 17 (b). In the present research, da/dN was based on the observed evolution of crack aspect ratio[35] as well as $d c / d N$ (calculated by the secant method). As can be seen, the data points are still quite scattered in both the shot peened cases, T1 and T0, and exhibit typical short fatigue crack behaviour. Generally, from the view point of $d a / d N$, the shot 
peening benefits were still obvious for some cracks, even in the more lightly shot peened case (T1) and this evaluation allows a reasonable comparison of crack growth rates under similar externally imposed stress/strain states, although local effects of work hardening or compensating residual stresses are ignored. For the T0 case, crack growth rates are generally well below those observed in the polished case, which indicates the intrinsic benefit of shot peening, even when the effect of the evolution of crack aspect ratio on $\Delta K$ (and hence $d a / d N$ ) is accounted for. However, the fatigue behaviour in the T1 case can be clearly identified as showing both types of behaviour as the crack growth data overlap with both the baseline polished condition as well as the T0 case.

The overall benefit of shot peening on fatigue behaviour is due to a complex interrelation of the effect of increased surface roughness, the compressive residual stress distribution in the surface as well as the work hardened layer, as evaluated and discussed in [35]. Due to the more intense shot peening process, the T0 condition has a rougher surface than the T1 condition (see Table 1). Mutoh et al. claimed that surface roughness produced by the shot peening process in an Al alloy contributed to the shorter crack initiation lives found when compared with the unpeened samples; the initial fatigue cracks were always sited at stress concentrations on the rough peened surface, especially the fold-like defects at a region of intense surface folding [3].

Compressive residual stress can significantly reduce fatigue crack propagation rate[40]. Interestingly, Mutoh et al. found that the point at which the smallest crack growth rate is found roughly corresponded to the point of maximum compressive residual stress [3]; the lower value of the crack aspect ratio in shot peened samples is the result of the sub-surface compressive residual stress caused by shot peening [3]. The decrease in the crack aspect ratio in the peened specimen in the surface layer is caused by the fact that the source of the crack in the peened specimen is always sited at a region of intense surface folding and the initial crack has a larger crack length on the surface [3].

It is well known that non-metallic inclusions are stress raisers and can initiate fatigue cracks. The $\mathrm{MnO}-\mathrm{SiO}-\mathrm{Al}_{2} \mathrm{O}_{3}$ family of inclusions in high strength steel is well known to be detrimental to fatigue properties while $\mathrm{MnS}$ stringers play a less dominant role (after [41]). The initiation of cracking at inclusions can be considered as occurring via three different possible processes: namely a slip band crack emanating from a debonded inclusion, the inclusion cracking due to impingement of slip bands and a slip-band crack emanating from an uncracked 
inclusion; the first normally occurs in high strength steels while the second and third mechanisms are typically observed in Al alloys [42]. In the present study, inclusions (Alumina/MnS) are the preferred fatigue crack initiation sites in the baseline (non-peened) condition. Debonding between inclusions and the matrix was seen for both Alumina and MnS inclusions at $170 \mu \mathrm{m}$ depth in the serial sectioning study, as indicated in Figure 18 (a) and (b), respectively. The occurrence of debonding between inclusion and matrix durng the fatigue process is considered to be the initial stage of crack initiation at an inclusion [41].

However, a difference between alumina dominated cracks and MnS dominated ones can be identified. In the former case, the alumina stringer is normally located in the central region of the crack (indicating it is the primary initiation site); while in the $\mathrm{MnS}$ initiation-dominated cracks, MnS particles are distributed along the fatigue crack path, in other words, fatigue crack growth directions in the current FV448 material were dominated by inclusions in both the surface and depth propagation directions.

In the shot peened condition, however, the fatigue crack initiation behaviour is controlled by the shot peening intensity: in the less intense shot peened condition, crack behaviour exhibits features of both the baseline and more intensely shot peened materials [35]. The more intense shot peened condition shows no evidence of fatigue cracks initiating from inclusions in either the serial sectioning and X-ray analysis results; instead surface roughness and preexisting small cracks from the shot peening process cause fatigue crack initiation. Due to the plastic deformation induced by the shot peening process, a thin work hardened layer is formed in the near surface layer. The microhardness depth profiles of the ground surface (before shot peening) and after shot peening are illustrated in Figure 19. The micro-hardness of the sample in the $\mathrm{T} 1$ condition appears to be slightly harder at a distance 50 to $65 \mu \mathrm{m}$ beneath the surface than the polished sample. However, measurement of the Vickers hardness closer to the surface than approximately $80-100 \mu \mathrm{m}$ would not give a reliable value according to British standard BS EN ISO 6507-1:2005 [43] and thus based on these measurements it is not possible to assess the extent and hardness of the work hardened layer beneath the surface in the T1 condition. However, for the T0 shot peened case, it is clear that the microhardness has increased significantly and this layer extends to around $350 \mu \mathrm{m}$ beneath the surface. It should be noted that the extent of the strain hardened layer and the 
compressive residual stress distributions have also been determined for these two conditions via X-ray diffraction in previous studies $[31,34]$ and the extent of both the strain hardened layer and the sub-surface zone of the residual compressive stress are greater in the T0 condition, and the maximum depth of the compressive residual stress zone also extends to $\sim 350 \mu \mathrm{m}$ beneath the surface. It seems likely therefore that microhardness evaluations are affected by both the strain hardened layer and the compressive residual stress zone.

The prediction of the fatigue strength is complicated, but studies have shown that the fatigue strength of steels is usually proportional to hardness and tensile strength [44], which leads us to expect a higher fatigue strength for a slightly harder steel. Therefore, if we assume there are equivalent areas of inclusion stringers in the unpeened, less intense (T1) as well as the intense shot peened (T0) samples, and these stringers are found at the surface, sub-surface and even in the interior, the variation in fatigue strength in these three different surface layers can be described qualitatively, as indicated in Figure 20.

In the baseline conditions (un-shot peened), the fatigue strength is constant in the depth direction; but in the regions near the surface stringers are apt to be vulnerable to fatigue crack initiation due to the stress concentration they provide. While in the less intensely shot peened condition (T1), the benefit of the slight increase in the fatigue strength in the near surface layer is limited in line with the limited improvement of hardness after $\mathrm{T} 1$ shot peening as well as the very thin shot peening affected layer. Therefore, the possibility of a fatigue-crack initiating from a stringer or surface defects (shot peened dimples) is similar. For the intensely shot peened condition, however, the fatigue strength improvement is strongest in the near surface layer, leading to a shallow fatigue crack shape. The inclusions in this condition therefore play a less important role in fatigue crack initiation, but it is the surface roughness induced defects produced during the severe plastic deformation in the shot peening process that preferentially initiate fatigue.

The above approximate relationship between fatigue strength and hardness in the near surface layer is in agreement with the experimental results: under similar strain range conditions, the beneficial effect of shot peening (in the T0 condition) was retained even at a high strain range level $\left(\Delta \varepsilon_{11}=0.68 \%\right)$, $\mathrm{N}_{\mathrm{f}, \mathrm{T} 1} \approx \mathrm{N}_{\mathrm{f} \text {,polished }}<\mathrm{N}_{\mathrm{f}, \mathrm{T} 0}$. However, the fatigue crack behaviour in the shot peened condition is complicated by the increased surface roughness which is detrimental to fatigue properties, and the compressive residual stress 
distribution that is considered to be beneficial in retarding crack propagation. Inclusions will be a more significant stress raiser in the unpeened condition, acting as fatigue crack initiators. The near-surface layer of the shot peened sample is in fact expected to undergo a complex superposition of the stress state due to the applied load with the residual stress distribution and its relaxation during subsequent fatigue; the local effects of work hardening from the shot peening may also be expected to affect this stress distribution (or the evolution of local strain). Therefore, in the less intensely shot peened condition (the T1 shot peened condition in the present study), the detrimental effect from the roughened surface is balanced out by the benefit of the work hardened layer and sub-surface compressive residual stress distribution. Thus the probability of a fatigue crack initiating from inclusions or surface roughness is almost the same. But for the intense shot peening condition (T0), the actual stress experienced in the near surface layer is expected to be significantly smaller than the applied stress due to stress superposition with the larger compressive residual stress distribution over a larger area. In this case, it is relatively easier for cracks to initiate on the shot peened surface (due to the pre-existing defects), but it is not easy for these cracks to propagate due to the complex interaction of the crack with the sub-surface strain hardened layer and the compressive residual stress layer. Beneath the shot peening affected zone, the fatigue strength is expected to be lower than that on the surface. Hence, fatigue cracks may be expected to propagate faster once they breakthrough the shot peened affected zone. 3-D tomography (by both serial sectioning and x-ray tomography) provides direct evidence that is unobtainable with conventional surface observations, revealing, for instance, the sub-surface crack coalescence in T0 shot peened conditions.

\section{Conclusions}

To the best of the authors' knowledge, there has been to date little information available in the literature on how the 3D fatigue crack morphology is affected by the shot peened layer. 2D serial sectioning is destructive, but can analyse larger volumes. A lab based X-ray tomography technique has enabled relatively high-resolution $(\sim 0.72 \mu \mathrm{m})$ post-test examination of a sufficient volume to provide three-dimensional characterisation of the crack shape and topography (i.e. fractography), but this technique cannot be used to scan larger volumes without compromising resolution.

The following conclusions can be reached from the present study: 
(1) In the unpeened sample, inclusions (alumina and $\mathrm{MnS}$ ) play an important role in early fatigue crack behaviour. They act as stress raisers, and thus crack initiators. For fatigue cracks initiated from alumina stringers, the crack morphology normally was dominated by only one (large) stringer, which was always in the central region of the crack; while the $\mathrm{MnS}$ inclusions seemed to dominate/affect the crack path in both the surface and depth crack growth directions as they formed in clusters.

(2) In the less intense shot peening condition (T1), fatigue crack morphology is similar to the baseline (unpeened) case. Cracking initiating from an alumina stringer was observed, but there was no clear evidence that subsurface crack coalescence occurred.

(3) For the intense shot peening condition, however, inclusions do not seem to affect crack behaviour. Sub-surface crack coalescence was also captured by both serial sectioning and X-ray tomography at around $150 \sim 180 \mu \mathrm{m}$ beneath the shot peened surface. This may be linked to both the extent of the compressive residual stress and the depth of the plastic deformation from the shot peening process. The shot peening process has "de-activated" the underlying metallurgical defect distribution, and substituted a surface roughness initiated defect population.

(4) Comparison with previous studies in this material under the same fatigue test conditions confirms that the beneficial role of shot peening is to slow crack propagation into the depth and that the evolution of both crack aspect ratio and the occurrence of crack coalescence events in the shot peened case can be linked to the extent of the work hardened layer and the compressive residual stress field. If insufficient shot peening intensity is applied, then the underlying metallurgical defect distribution still operates, and can outweigh any (limited) effect from a very thin work hardened layer and compressive residual stress zone.

\section{Acknowledgement}

Financial support from China Scholarship Council, as well as E.ON Technologies (Ratcliffe) Ltd. is gratefully acknowledged. Thanks are extended to Dr Iain Paterson and Dr Kath Soady of E.ON Technologies (Ratcliffe) Ltd. for helpful discussions. The authors would also like to acknowledge the $\mu$-VIS $\mathrm{X}$-Ray imaging centre of the University of Southampton for provision of tomographic imaging facilities, supported by EPSRC grant EP-H01506X and 
the invaluable support of Dr. Richard Boardman in the $\mu$-VIS centre of the University of Southampton.

\section{Figures}

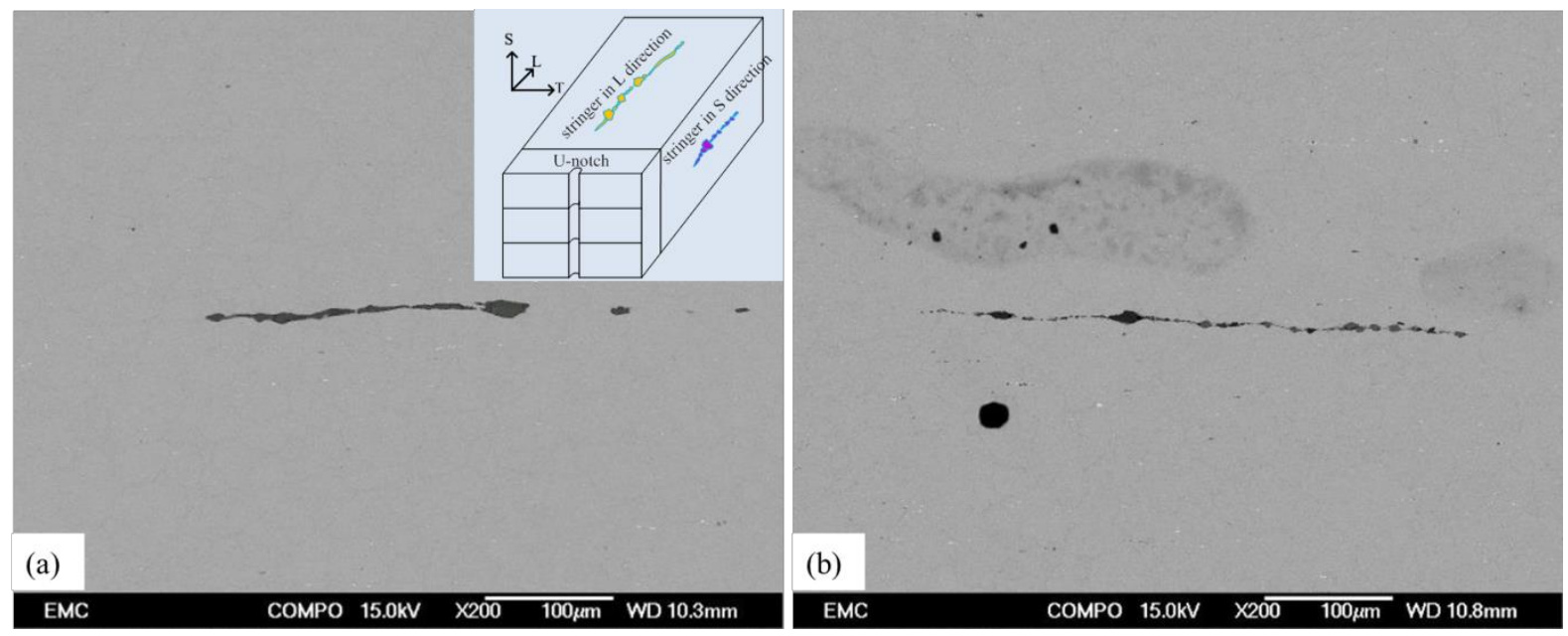

Figure 1 The schematic illustration in (a) shows the positions of the stringers in the barstock; inclusions of aluminium oxide/silicate and manganese sulphide aligned in the longitudinal direction (a) on the L-T face; (b) on the L-S face within the FV448 matrix.

Table 1 Surface condition of the test matrix

\begin{tabular}{ccc}
\hline $\begin{array}{c}\text { Surface } \\
\text { condition }\end{array}$ & Process parameter & $\begin{array}{c}\text { Surface roughness } \\
\text { Ra }(\boldsymbol{\mu m})\end{array}$ \\
\hline polished & Baseline condition, polished down to $1 \mu \mathrm{m}$ & - \\
T1 & $\begin{array}{c}\text { Intensity 4 A, coverage } 200 \% \text {, shot diameter } 0.28 \mathrm{~mm}, \\
\text { shot diameter 45-52 } \mathrm{HRC} \text {, shot velocity } 26 \mathrm{~ms}^{-1}\end{array}$ & 1.25 \\
& $\begin{array}{c}\text { Intensity } 13 \mathrm{~A}, \text { coverage } 200 \% \text {, shot diameter } 0.58 \mathrm{~mm}, \\
\text { shot diameter } 45-52 \mathrm{HRC} \text {, shot velocity } 57 \mathrm{~ms}^{-1}\end{array}$ & 3.6 \\
\hline
\end{tabular}



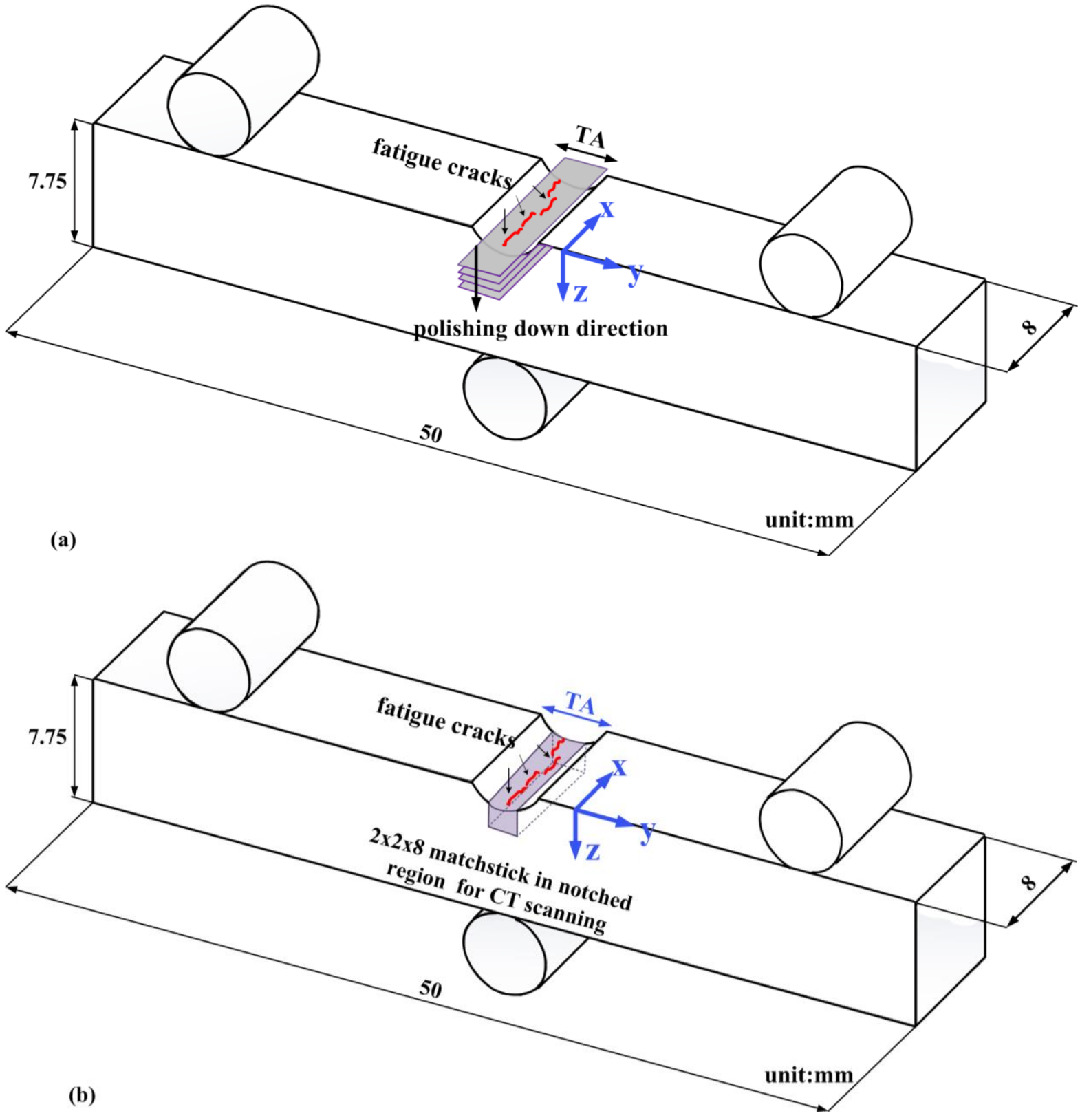

Figure 2 Sample geometry schematic with a three-point bend set up: (a) illustrates the polishing direction in the serial sectioning process; (b) shows the matchstick taken from the notch region for Xray computed tomography imaging. 


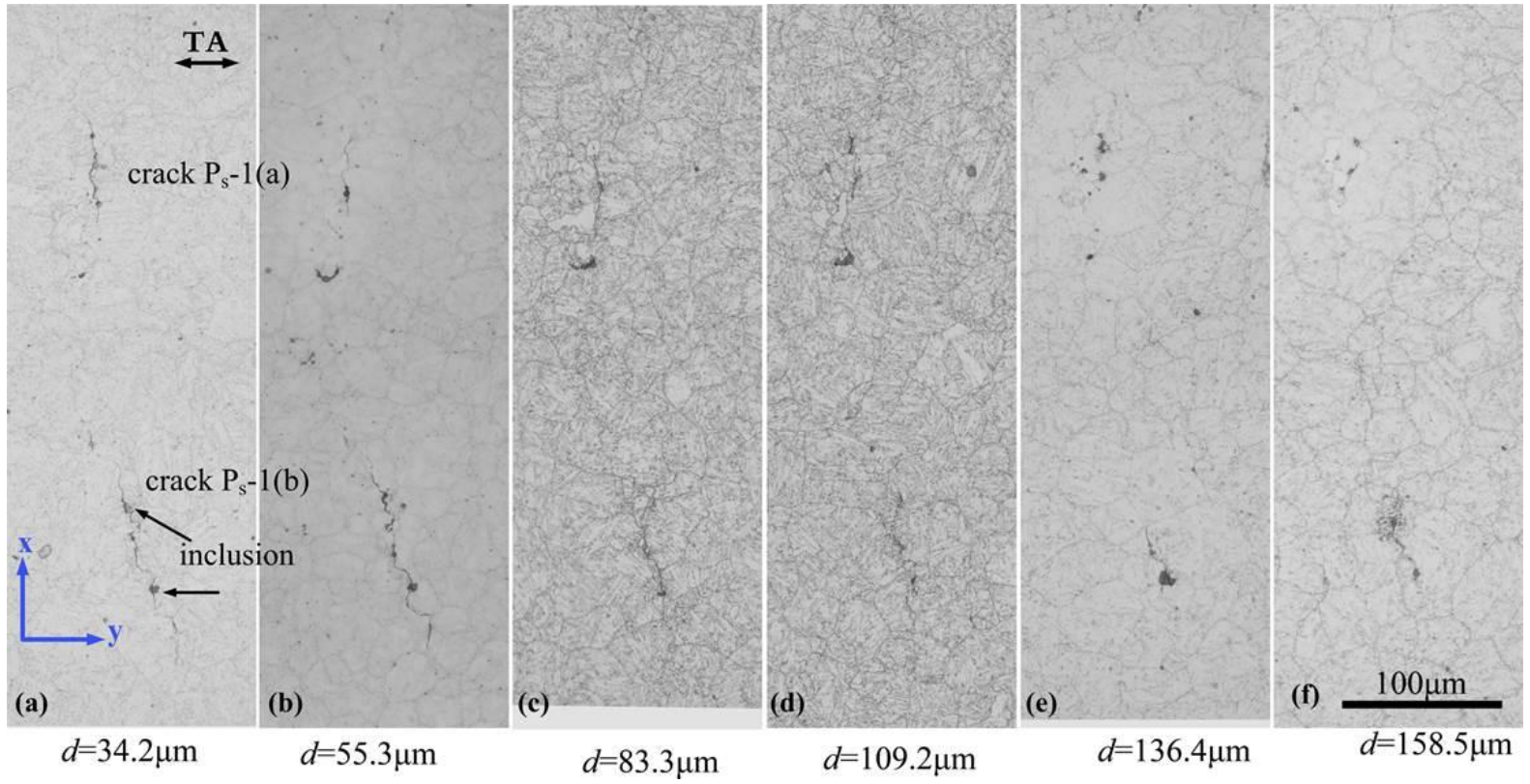

Figure $32 \mathrm{D}$ slices of the serial sectioning illustrating the varied morphology of crack $\mathrm{P}_{\mathrm{s}}-1$ at different depths beneath the surface. MnS particles are observed on both the crack paths of crack $\mathrm{P}_{\mathrm{s}}-1$ (a) and crack $\mathrm{P}_{\mathrm{s}}-1(\mathrm{~b})$.

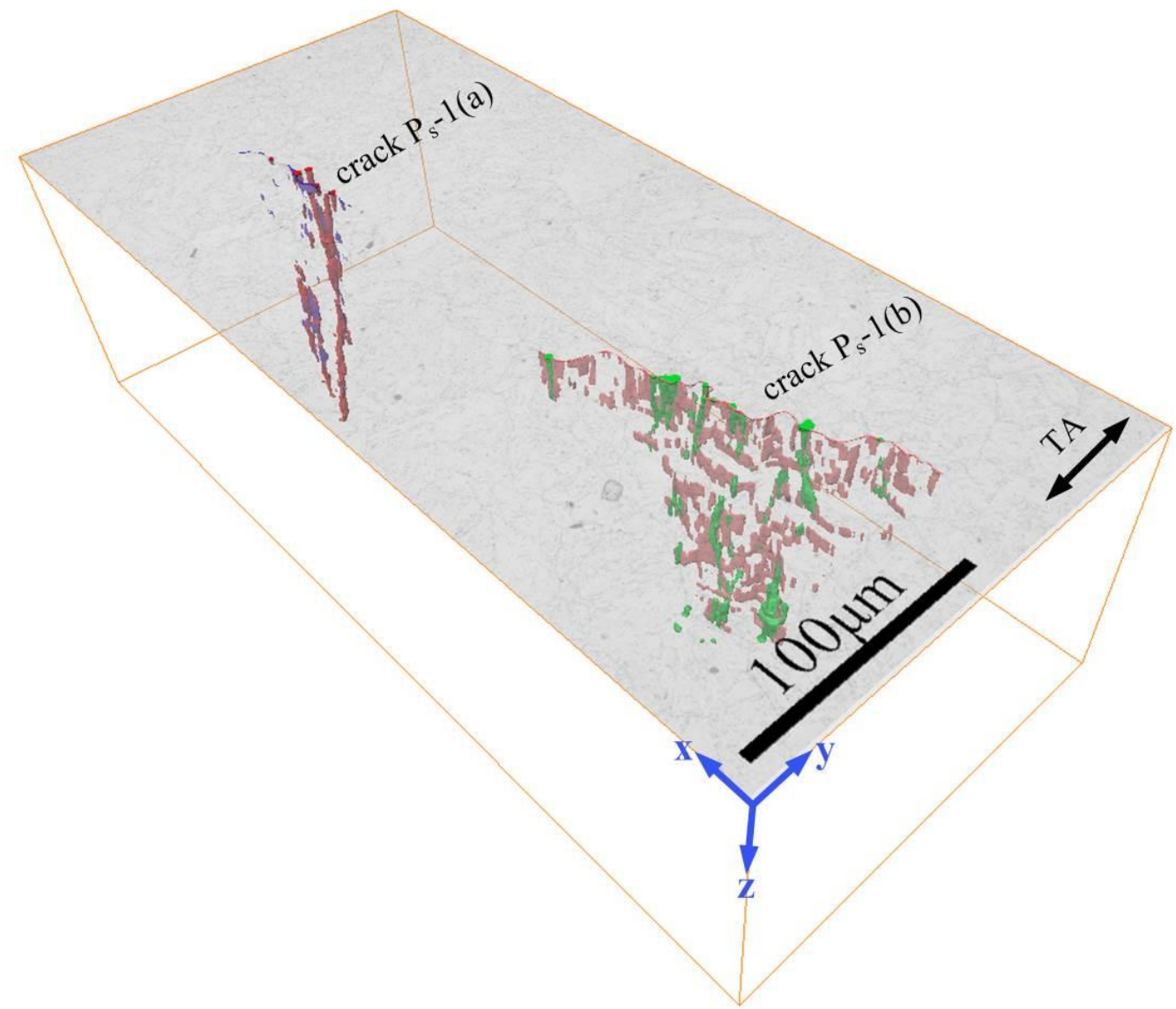

Figure 4 3D reconstruction view of crack $\mathrm{P}_{\mathrm{s}}-1$ based on 2D slices of the serial sectioning. The red and green regions indicate the $\mathrm{MnS}$, while the blue and orange coloured regions represent the fatigue crack. 


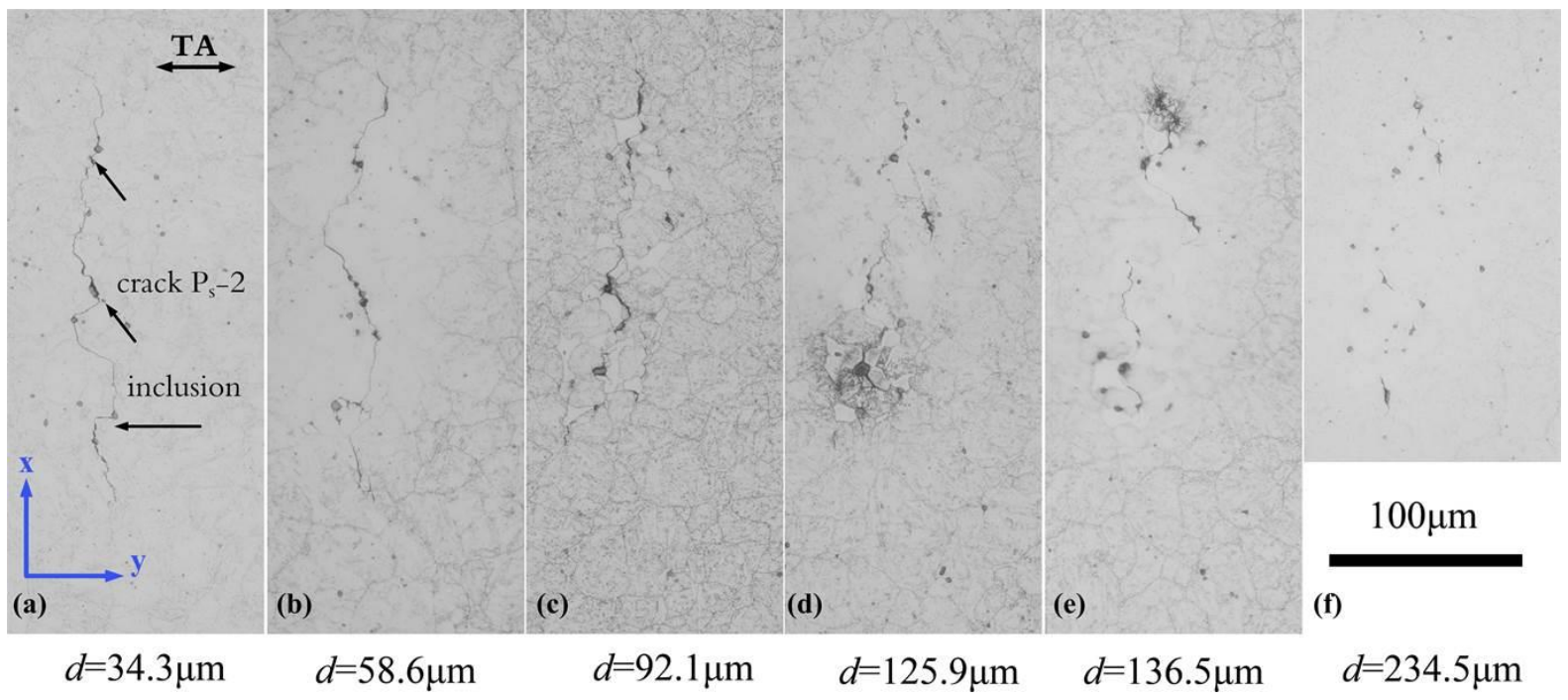

Figure $52 \mathrm{D}$ slices of the serial sectioning illustrating the varied morphology of crack $\mathrm{P}_{\mathrm{s}}-2$ at different depths beneath the surface.

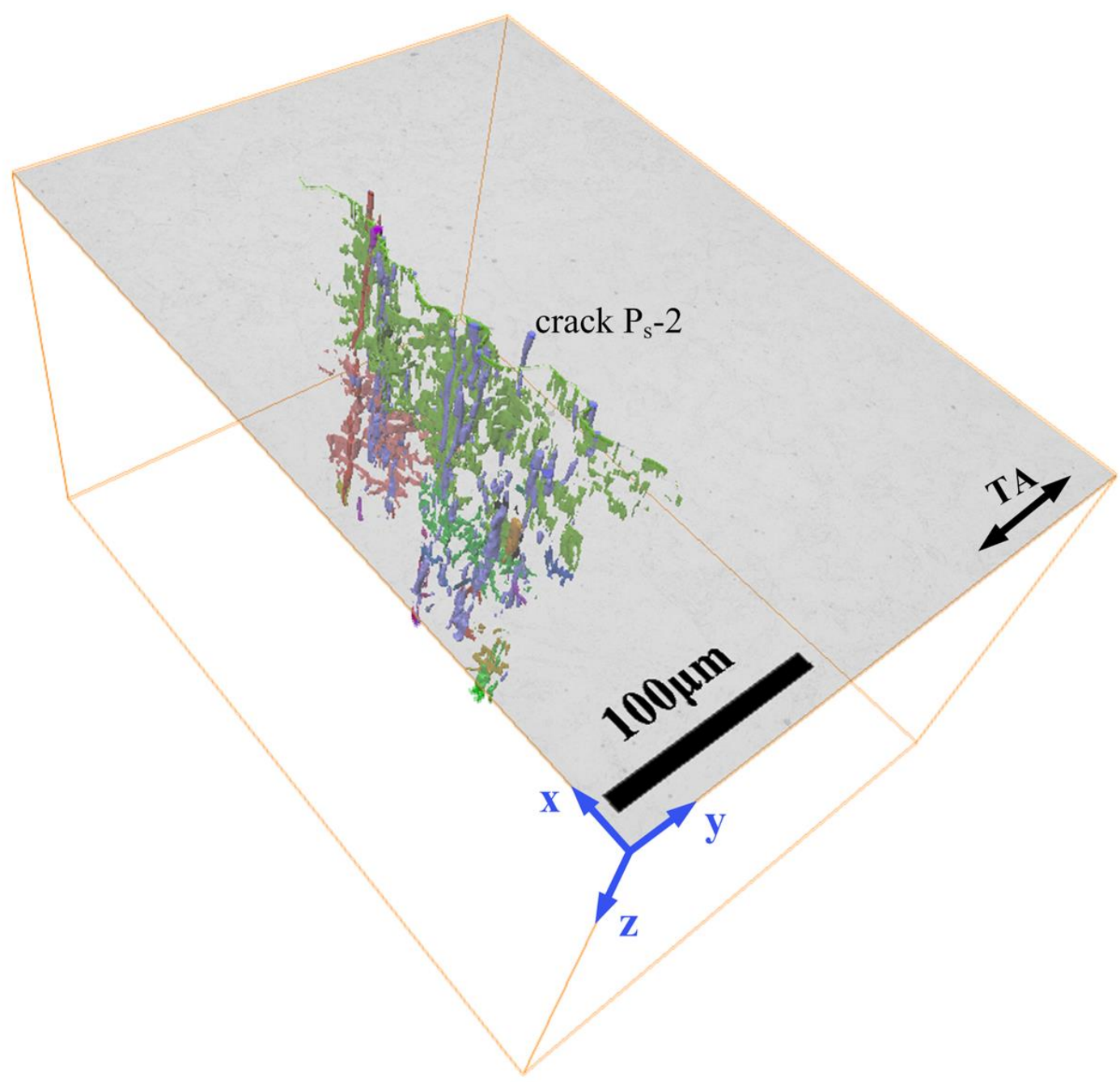

Figure $63 \mathrm{D}$ reconstruction view of crack $\mathrm{P}_{\mathrm{s}}-2$ based on $2 \mathrm{D}$ slices of the serial sectioning. The green and red regions represent the fatigue crack while the $\mathrm{MnS}$ particles are coloured blue. 

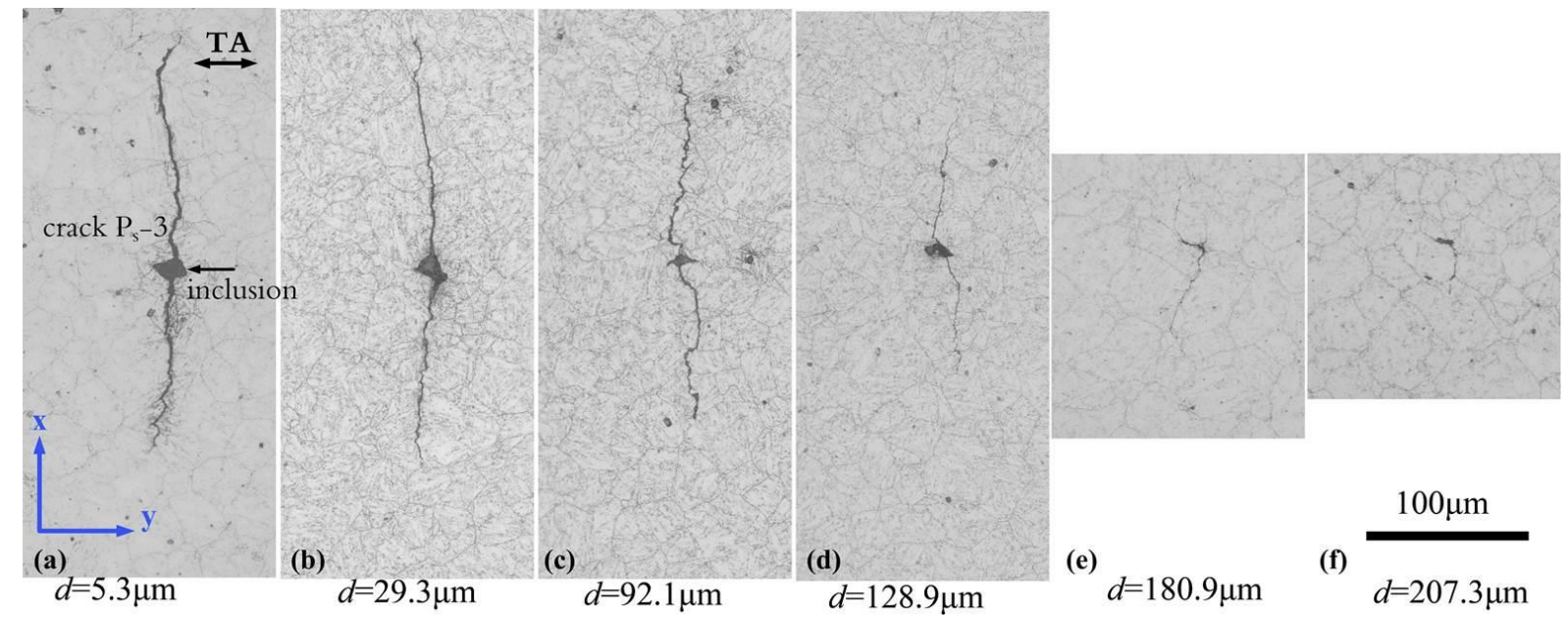

Figure $72 \mathrm{D}$ slices of the serial sectioning illustrating the varied morphology of crack $\mathrm{P}_{\mathrm{s}}-3$ at different depths beneath the surface.

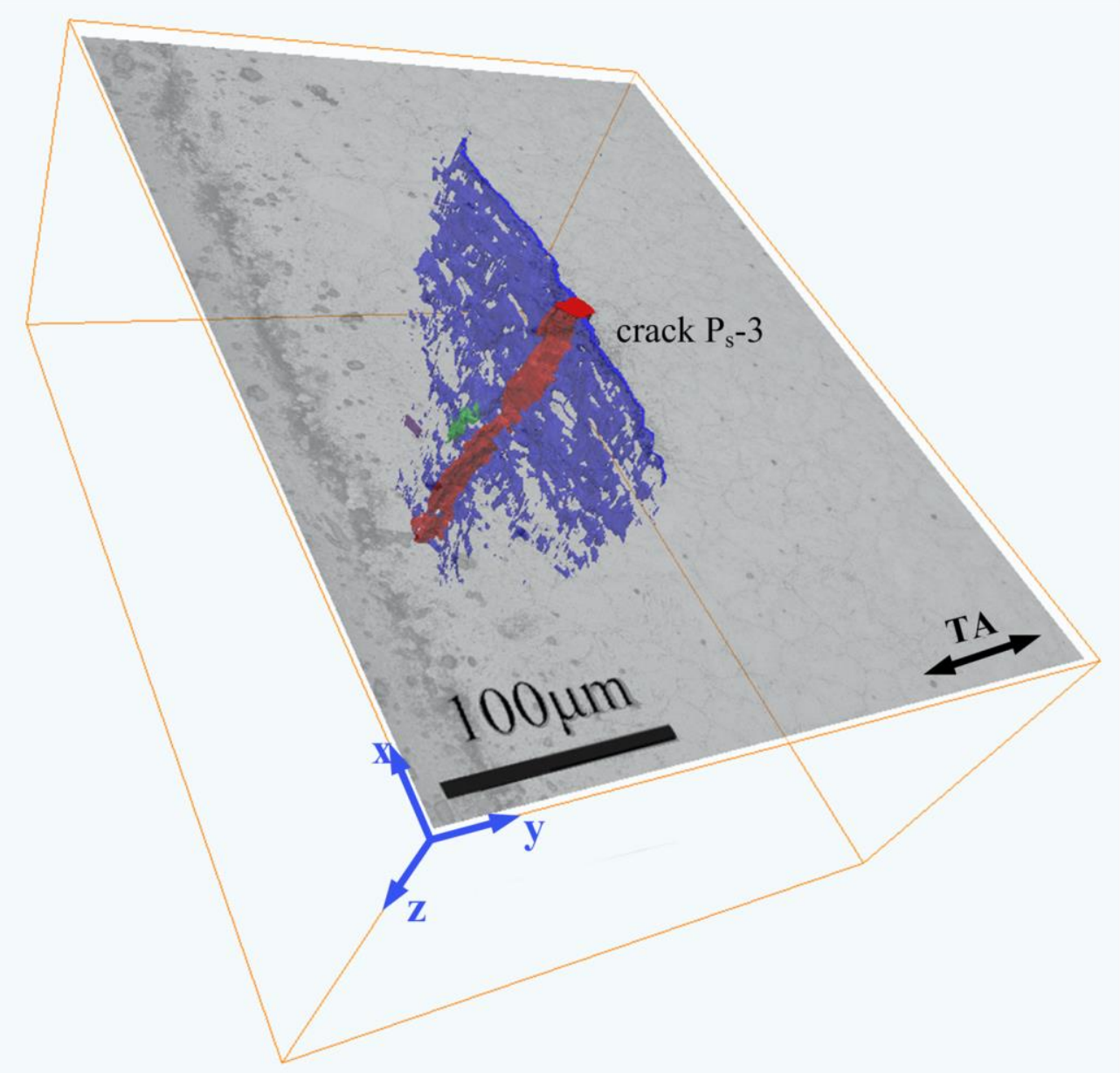

Figure $83 \mathrm{D}$ reconstruction view of crack $\mathrm{P}_{\mathrm{s}}-3$ based on $2 \mathrm{D}$ slices of the serial sectioning. The blue regions represent the fatigue crack while the alumina stringers are coloured red and green. 


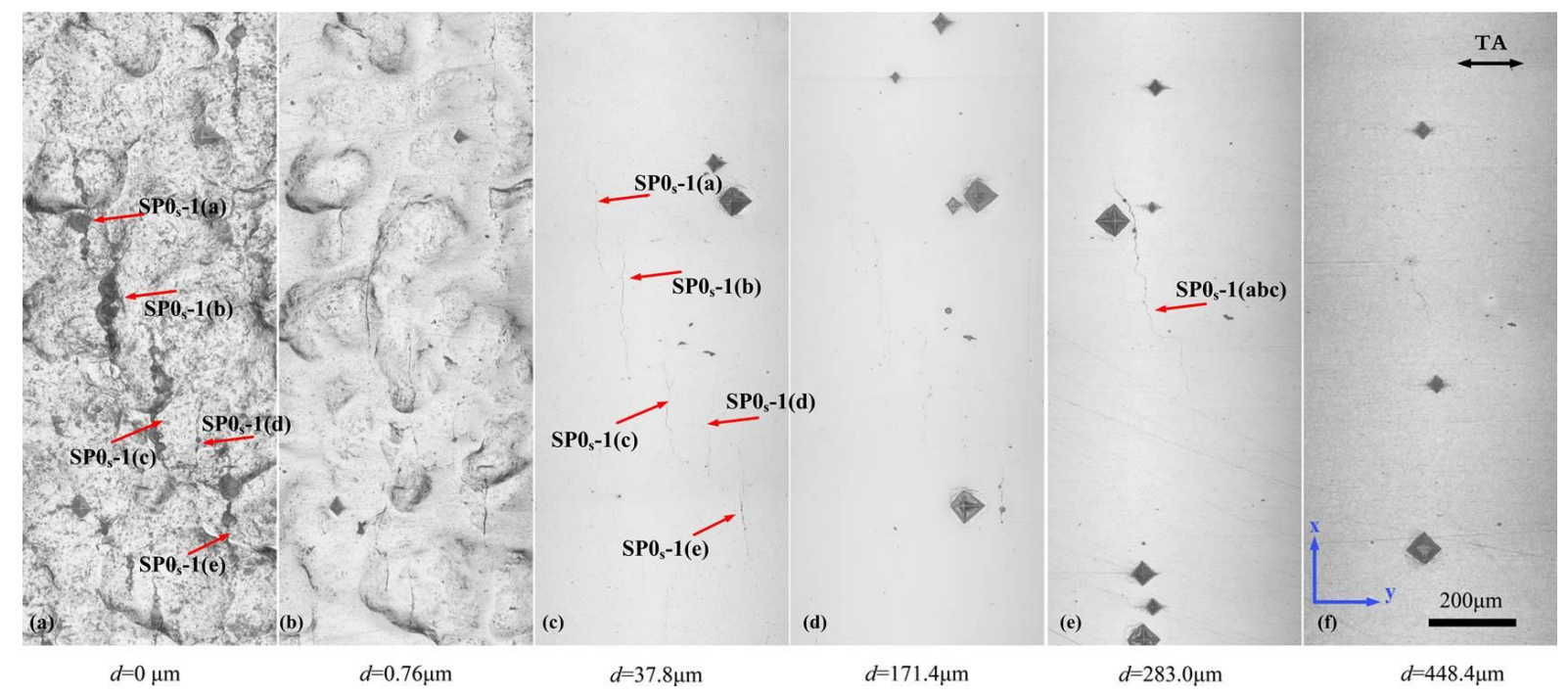

Figure $92 \mathrm{D}$ slices of the serial sectioning illustrating the varied morphology of crack $\mathrm{SP}_{\mathrm{s}}-1$ at different depths beneath the surface. 


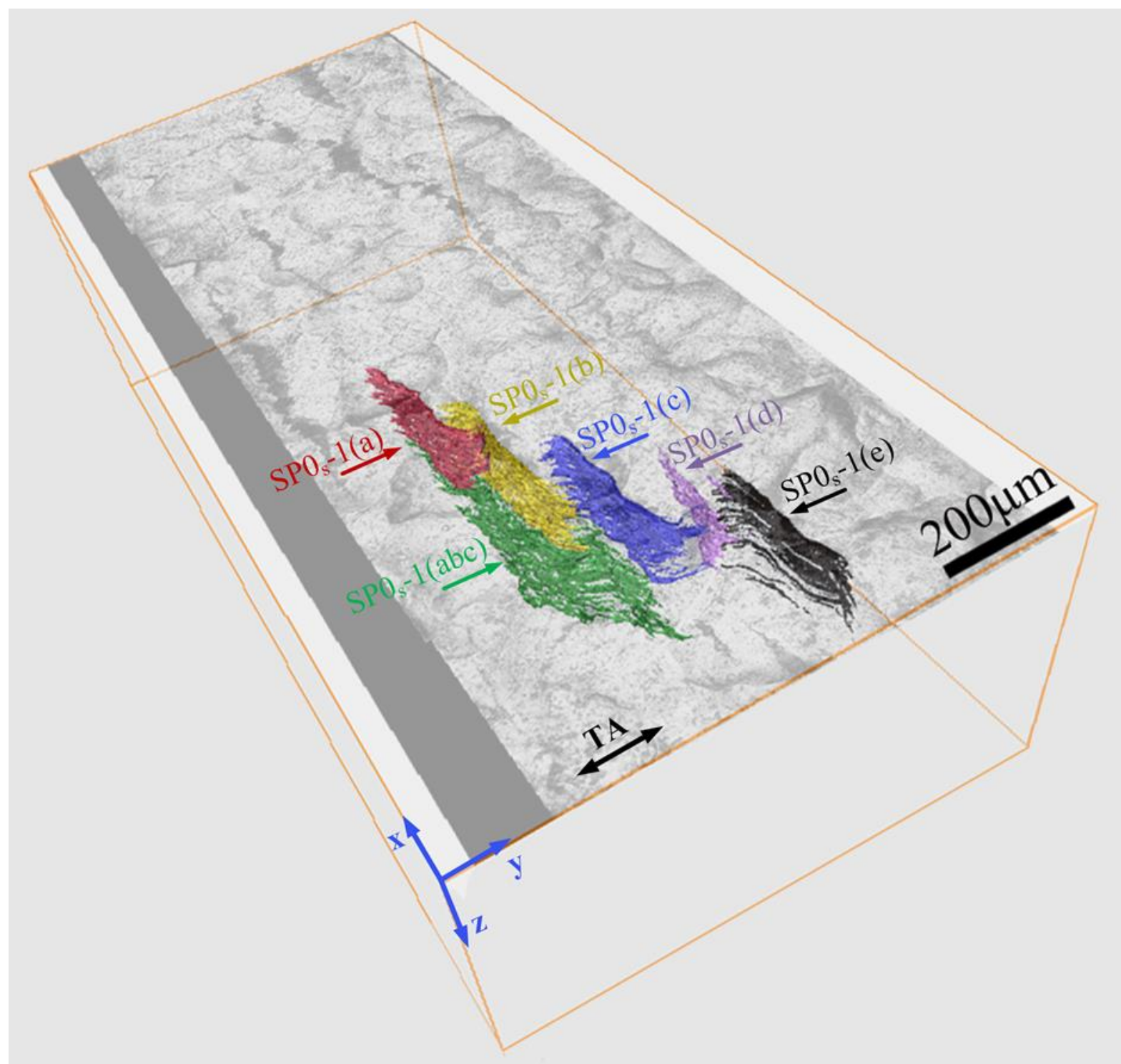

Figure 10 3D reconstruction view of crack SP0s-2 based on 2D slices of the serial sectioning. The cracks recognized on the shot peened surface are labelled as crack SP0s-(a), SP0s-(b), SP0s-(c), SP0s1(d), SP0s-1(e), and coloured red, yellow, blue, pink and black, respectively. The sub-surface coalesced crack is indicated by the green crack SP0s-1(abc). 


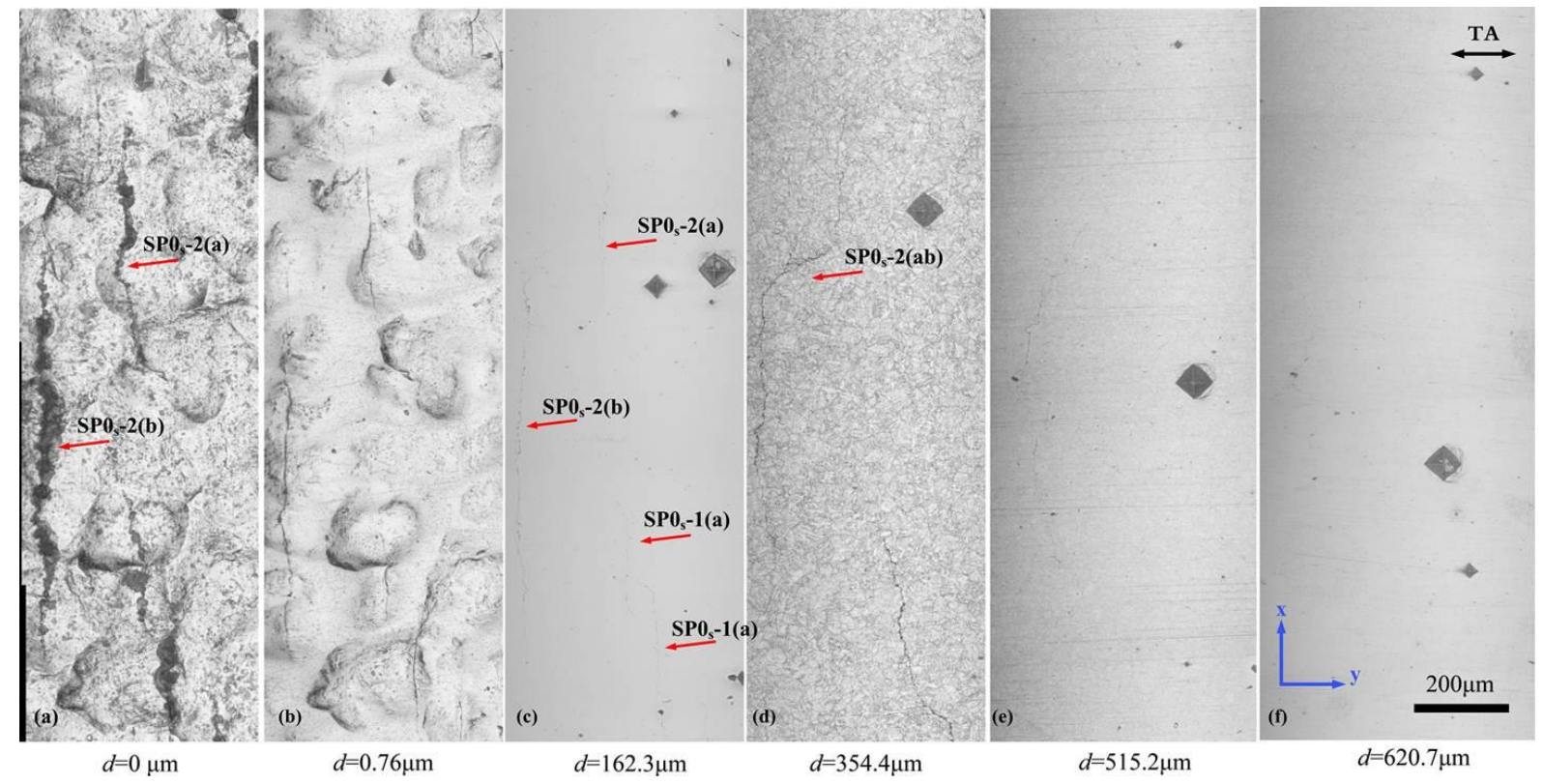

Figure $112 \mathrm{D}$ slices of the serial sectioning illustrating the varied morphology of crack $\mathrm{SP}_{\mathrm{s}}-2$ at different depths beneath the surface. 


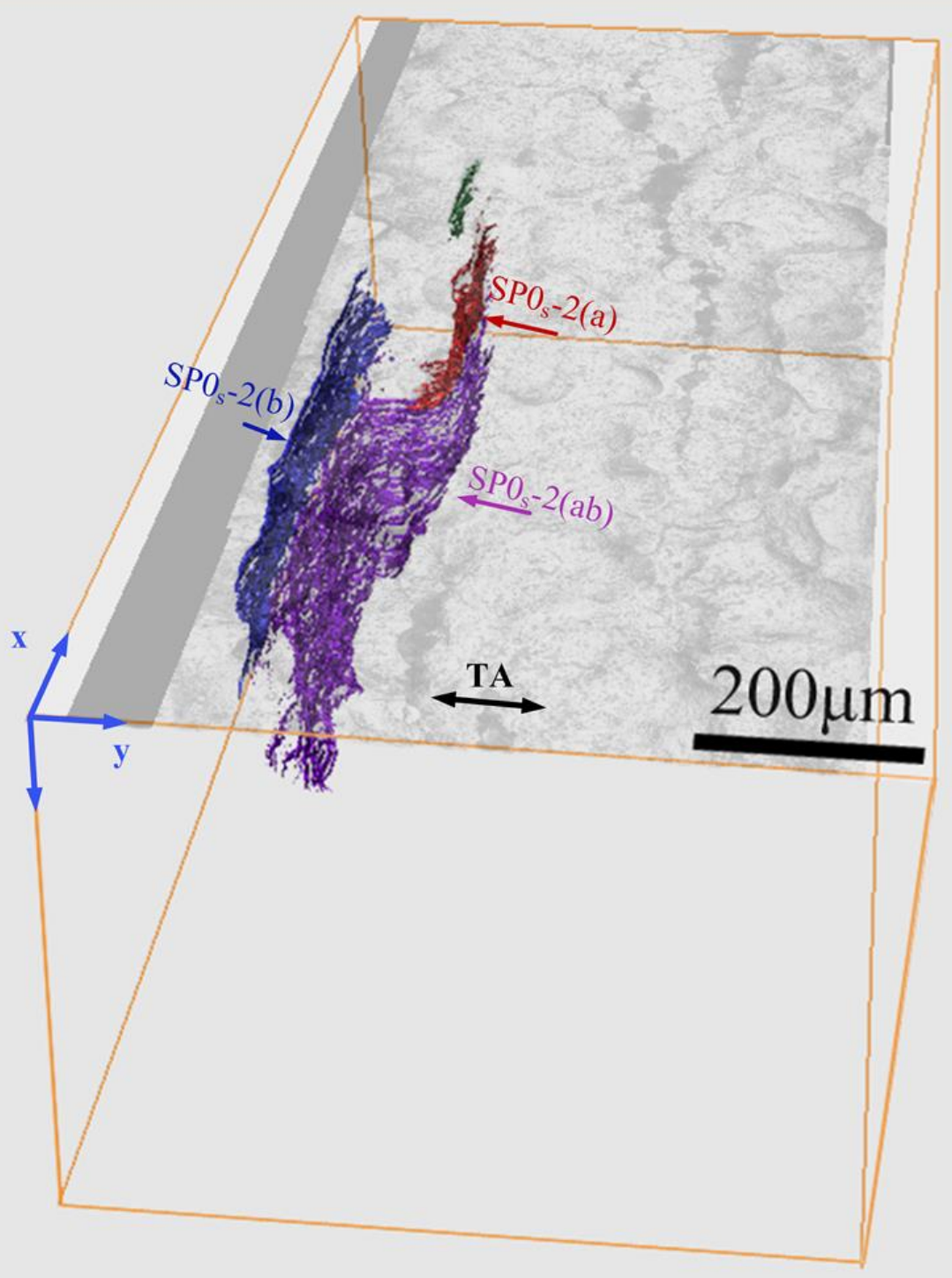

Figure $123 \mathrm{D}$ reconstruction view of crack $\mathrm{SP}_{\mathrm{s}}-2$ based on $2 \mathrm{D}$ slices of the serial sectioning. The cracks recognised on the shot peened surface are labelled as crack SP0s-2(a), SP0s-2(b), and coloured red and yellow, respectively. The sub-surface coalesced crack is indicated as a purple crack SP0s$2(a b)$. 

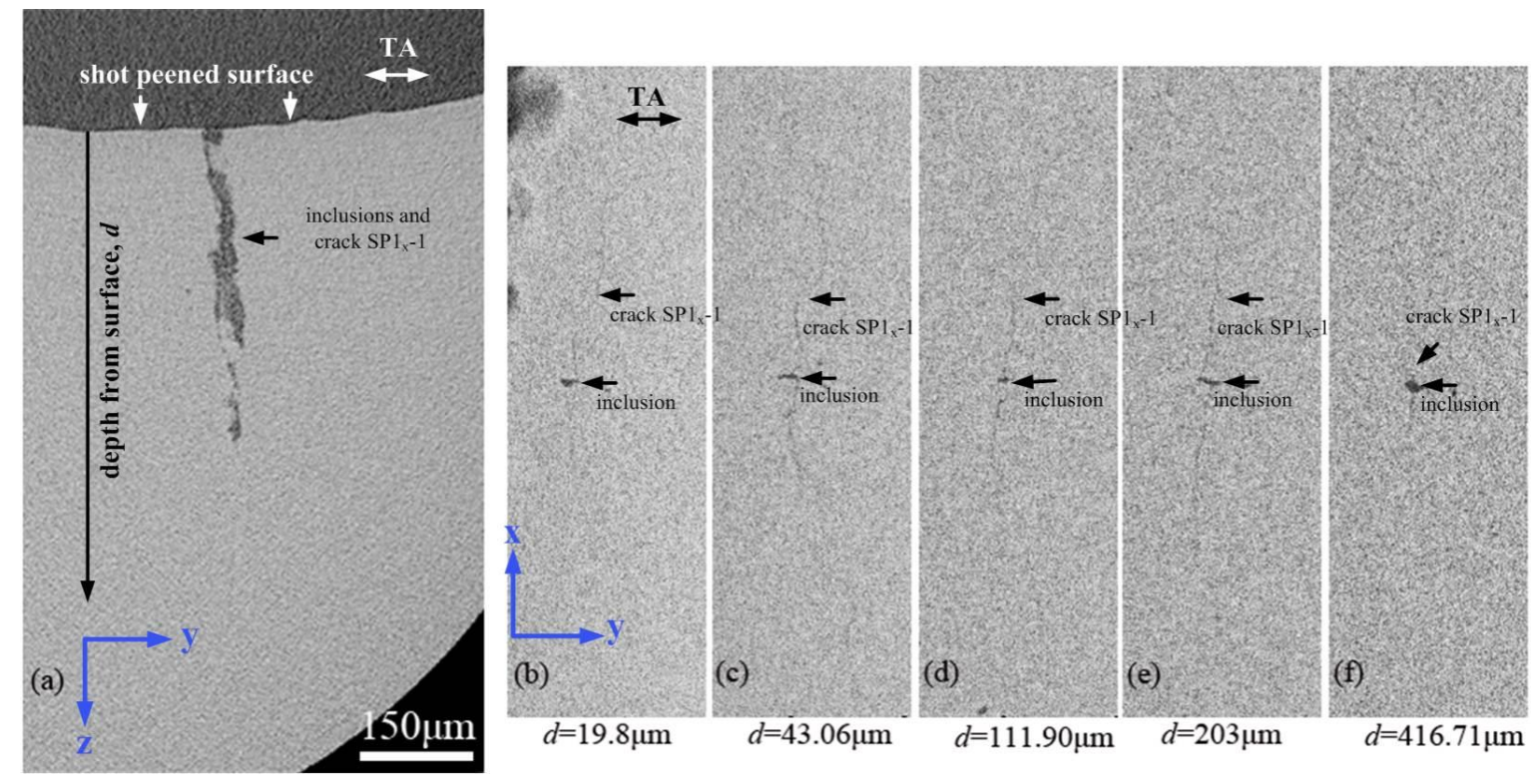

Figure 13 (a) Reconstruction of a single 2D slice of the cross section of fatigue crack SP1 $1_{x}-1$ and inclusions in $\mathrm{T} 1$ shot peened case; (b) -(f) series of 2D reconstruction of $\mathrm{X}-\mathrm{Y}$ plane showing the fatigue crack SP1 $1_{x}-1$ and its morphology change along the depth direction.

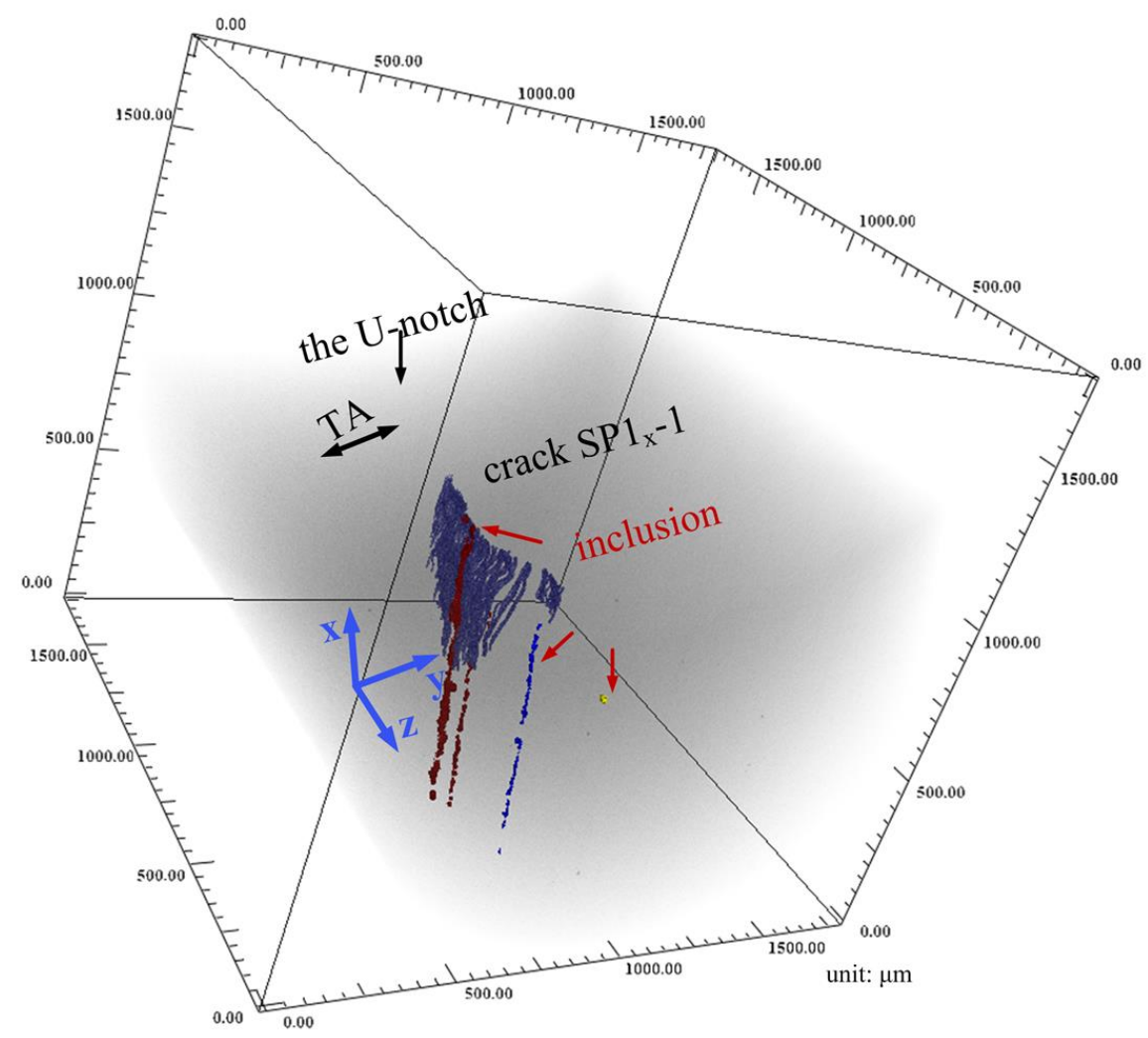

Figure $143 \mathrm{D}$ reconstruction of the segmented fatigue crack $\mathrm{SP} 1_{\mathrm{x}}-1$ and inclusion in $\mathrm{T} 1$ shot peened conditions. The fatigue crack was labelled blue while the inclusions are red, yellow as well as light blue; the opaque indicates the matrix volume. 


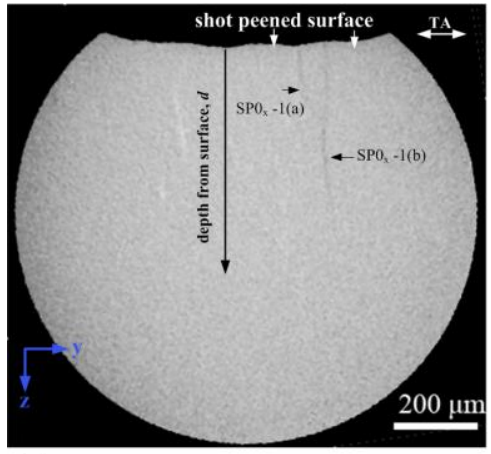

(a)
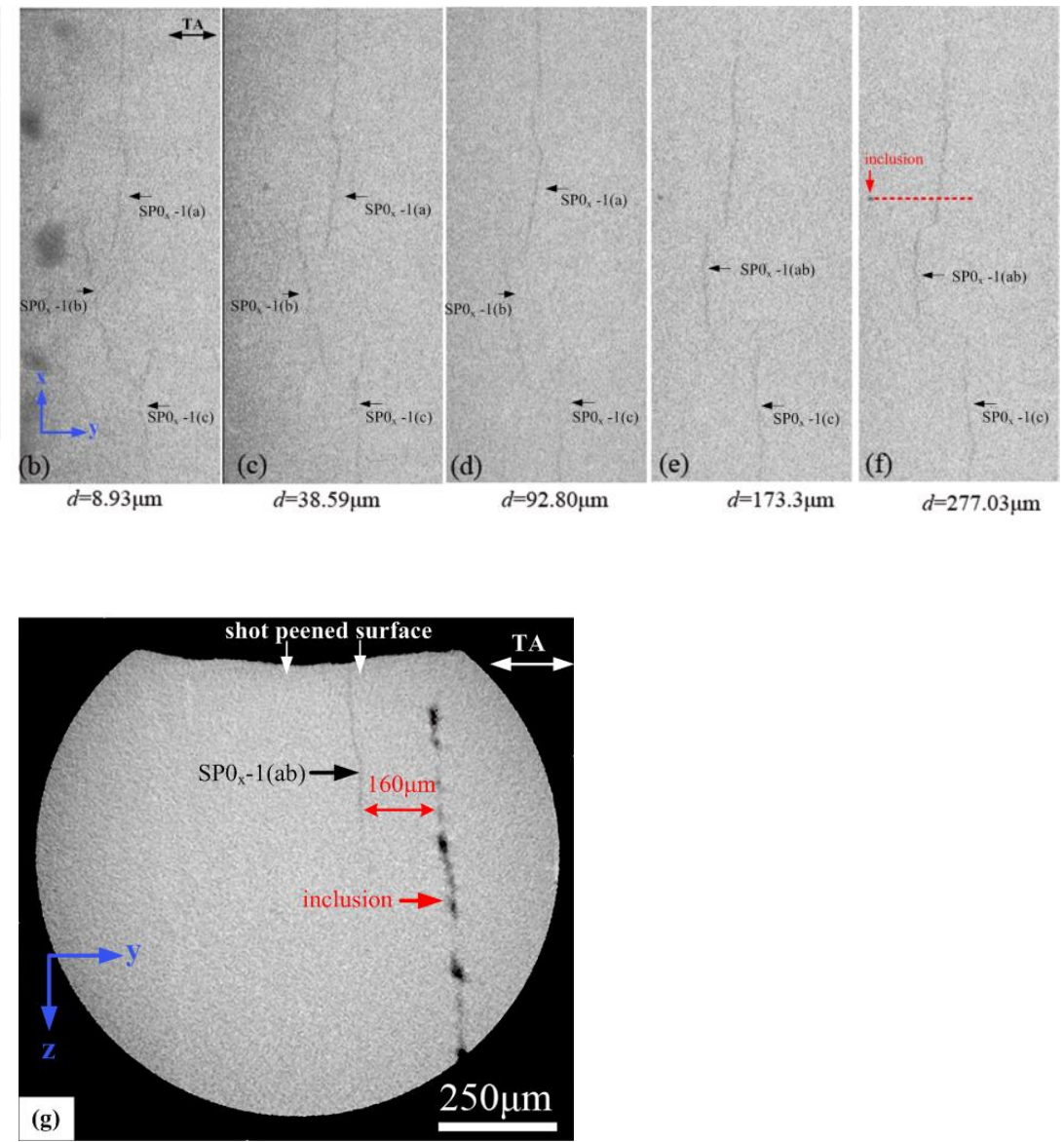

Figure 15 (a) Reconstruction of a single 2D slice of the cross section of fatigue crack $\mathrm{SP}_{\mathrm{x}}-1$ (a) and $\mathrm{SP}_{\mathrm{x}}-1(\mathrm{~b})$ in $\mathrm{T} 0$ shot peened condition: (b)-(f) series of $2 \mathrm{D}$ reconstruction of $\mathrm{X}-\mathrm{Y}$ plane showing the $\mathrm{SP}_{\mathrm{x}}-1(\mathrm{a}), \mathrm{SP}_{\mathrm{x}}-1(\mathrm{~b}) \mathrm{SP}_{\mathrm{x}}-1(\mathrm{c})$, indicating how the crack morphologies change along the depth direction; (g) shows the cross section of crack $\mathrm{SP}_{\mathrm{x}}-1(\mathrm{ab})$ and the inclusion stringer. 


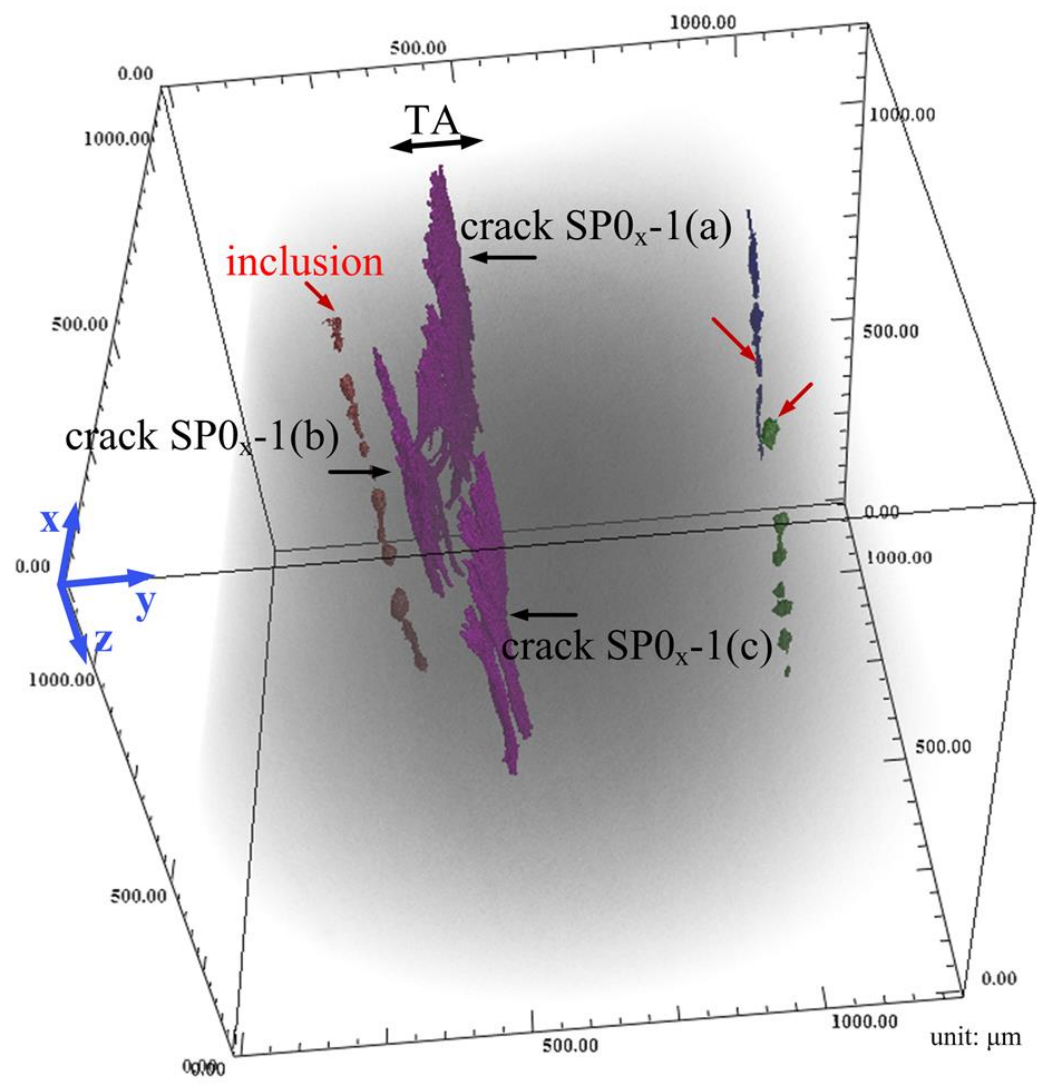

Figure 16 3D reconstruction of fatigue crack and inclusion in T0 shot peened conditions. The fatigue crack was labelled blue while the inclusions were in red, yellow as well as a light blue colour, the opaque indicates the matrix volume.
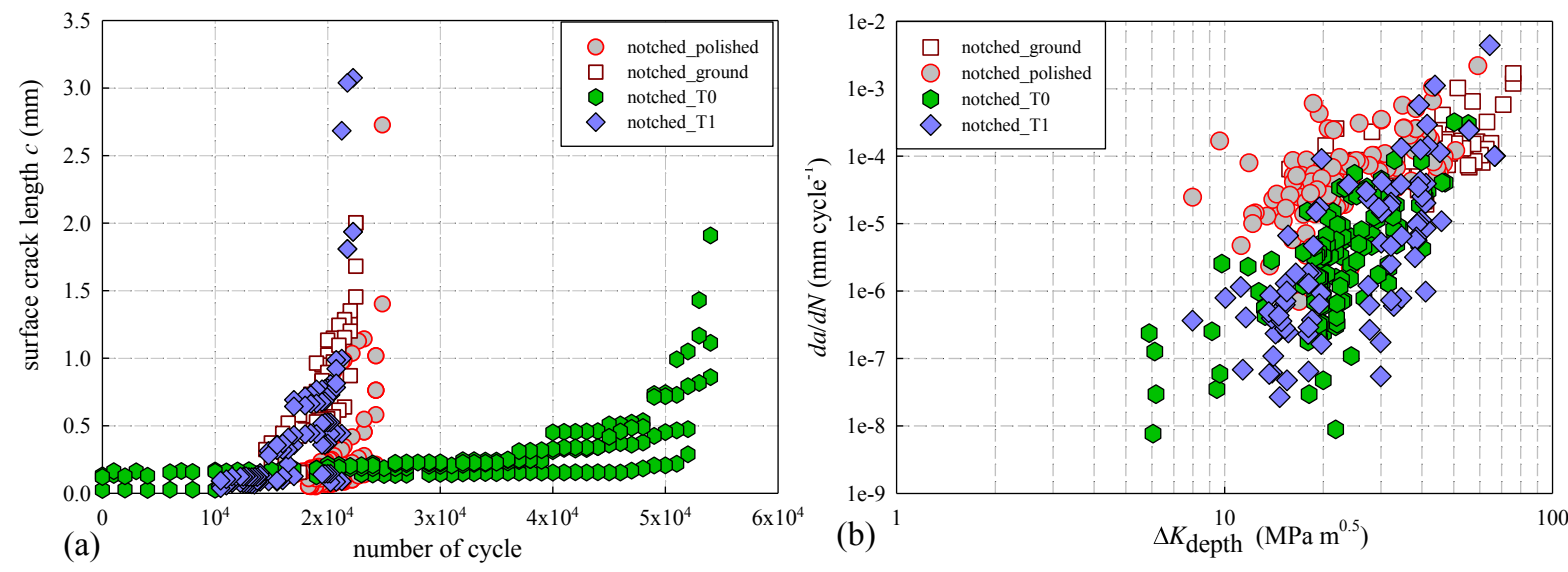

Figure 17 (a) Half surface crack length $\mathrm{c}$ at different cycles of fatigue life; (b) a Linear Elastic Fracture Mechanics (LEFM) calculation of $K$-equilibrium around the crack front was conducted based on Scott and Thorpe's review paper and the fatigue crack propagation rate $d a / d N$ is plotted against stress intensity factor range $\Delta K_{\text {depth }}[35]$. 


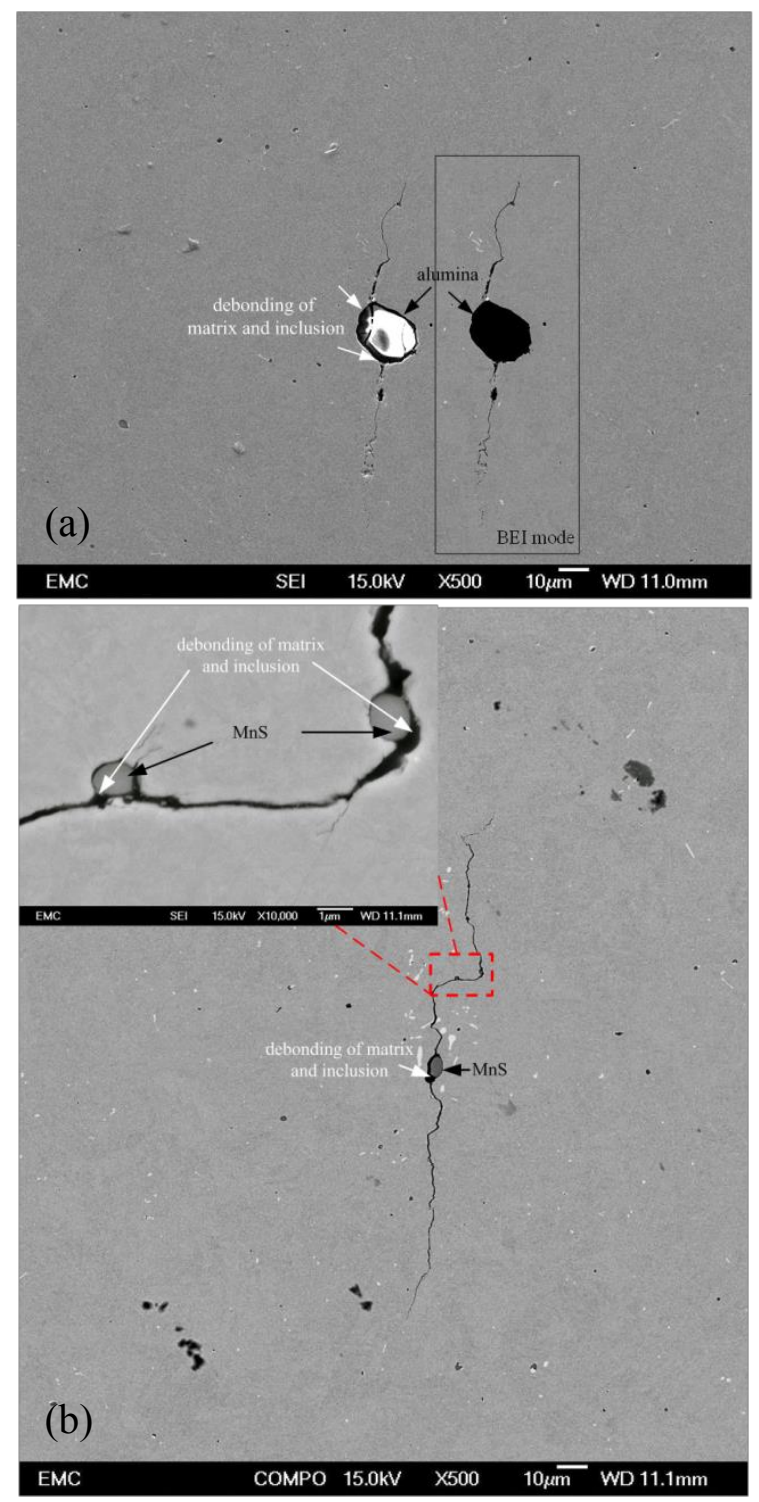

Figure 18 The debonding of matrix and (a) alumina, and (b) MnS found on the fatigue crack paths at the depth of $200 \mu \mathrm{m}$.

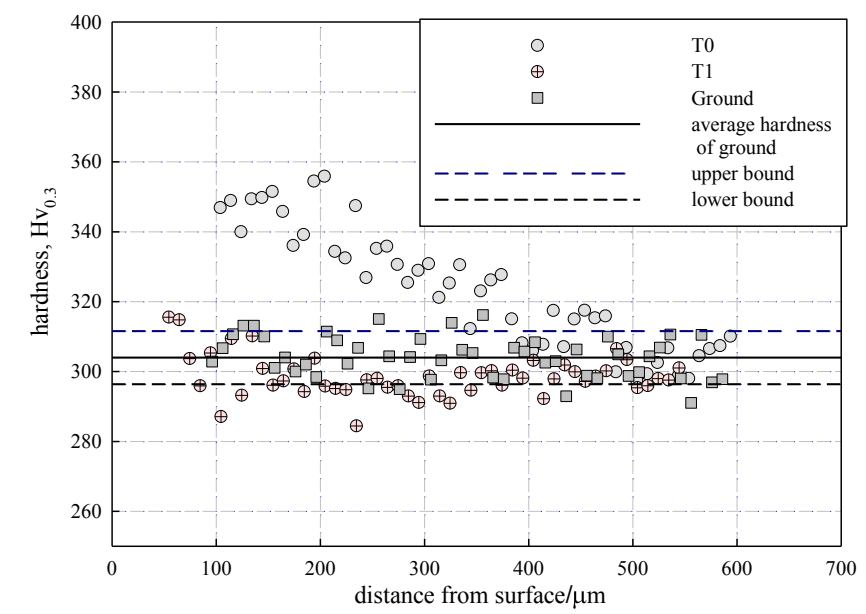


Figure 19 Comparison of micro-hardness distribution in the depth direction in ground, T0 and $\mathrm{T} 1$ shot peening conditions
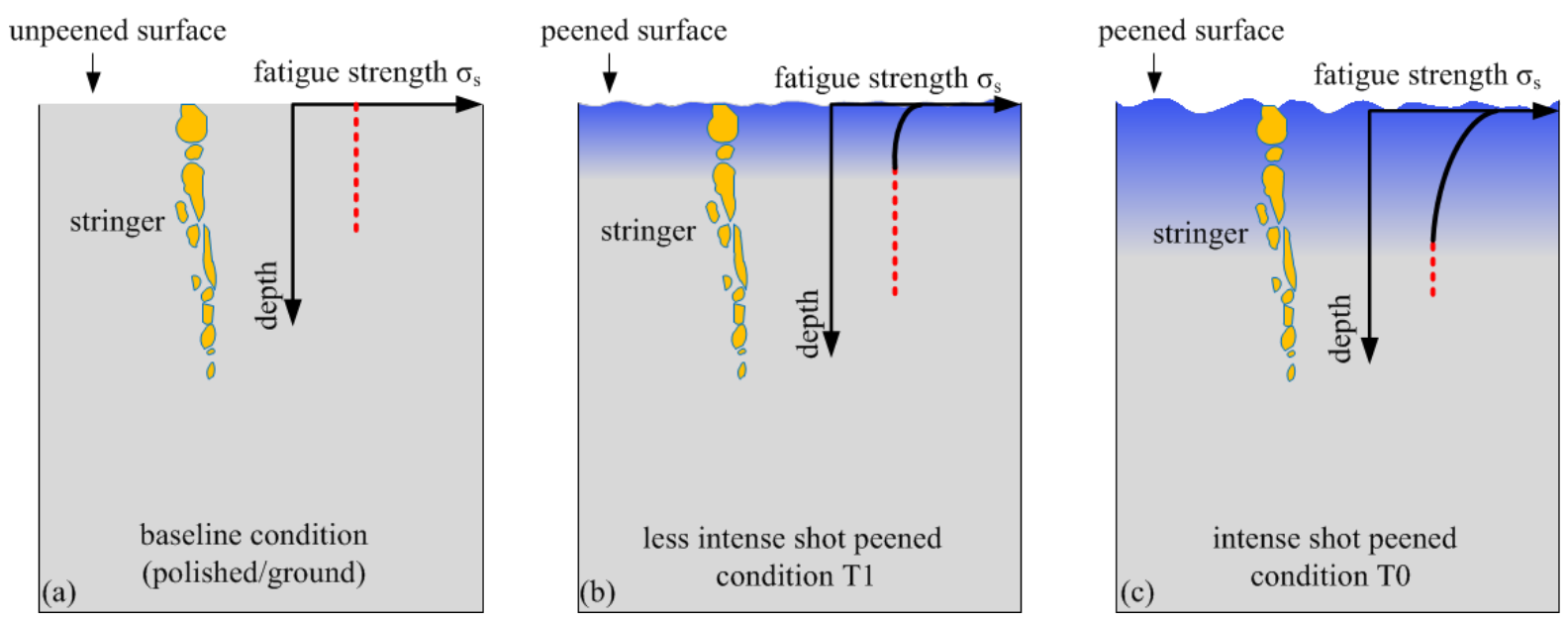

Figure $20 \mathrm{~A}$ schematic of the fatigue limit in the near surface layers based on the microhardness values as a function of depth beneath the shot peened surface (assuming the areas of stringers are the same in these three conditions): (a) baseline condition: (b) less intense shot peened condition $\mathrm{T} 1$ and (c) intense shot peened condition $\mathrm{T} 0$.

\section{References}

[1] in: ASTM E647-08, American Society for Testing and Materials: Standard Test Method for Measurement of Fatigue Crack Growth Rates.

[2] D. Taylor, J.F. Knott, Fatigue \& Fracture of Engineering Materials \& Structures, 4 (1981) 147-155.

[3] Y. Mutoh, G.H. Fair, B. Noble, R.B. Waterhouse, Fatigue \& Fracture of Engineering Materials \& Structures, 10 (1987) 261-272.

[4] K. Shiozawa, Y. Morii, S. Nishino, L. Lu, Int. J. Fatigue, 28 (2006) 1521-1532.

[5] Q.Y. Wang, C. Bathias, N. Kawagoishi, Q. Chen, Int. J. Fatigue, 24 (2002) 1269-1274.

[6] K.J. Miller, Fatigue \& Fracture of Engineering Materials \& Structures, 5 (1982) 223-232.

[7] K.S. Ravichandran, J.M. Larsen, X.D. Li, in: K.S. Ravichandran, R.O. Ritchie, Y. Murakami (Eds.) Small Fatigue Cracks: Mechanics, Mechanisms, and Applications 1999.

[8] K.S. Ravichandran, J.M. Larsen, Fatigue \& Fracture of Engineering Materials \& Structures, 16 (1993) 909-930.

[9] P. Clement, J.P. Angeli, A. Pineau, Fatigue \& Fracture of Engineering Materials \& Structures, 7 (1984) 251-265.

[10] S.I. Lieberman, A.M. Gokhale, S. Tamirisakandala, Scripta Materialia, 55 (2006) 63-68.

[11] J.E. Spowart, Scripta Materialia, 55 (2006) 5-10.

[12] W. Schaef, M. Marx, H. Vehoff, A. Heckl, P. Randelzhofer, Acta Mater., 59 (2011) 1849-1861.

[13] M.A. Groeber, B.K. Haley, M.D. Uchic, D.M. Dimiduk, S. Ghosh, Materials Characterization, 57 (2006) 259-273.

[14] M.D. Uchic, M.A. Groeber, D.M. Dimiduk, J.P. Simmons, Scripta Materialia, 55 (2006) 23-28.

[15] D.J. Rowenhorst, A. Gupta, C.R. Feng, G. Spanos, Scripta Materialia, 55 (2006) 11-16.

[16] C. Schoettle, P.A.S. Reed, M.J. Starink, I. Sinclair, D.J. Child, G.D. West, R.C. Thomson, in: 12th international symposium on superalloys, John Wiley \& Sons, Inc., Seven Springs, PA, USA, 2012.

[17] S.R. Stock, International Materials Reviews, 44 (1999) 141-164.

[18] S.R. Stock, International Materials Reviews, 53 (2008) 129-181.

[19] M. E., W.P. J., International Materials Reviews, 59 (2014) 1-43.

[20] J.C. Elliott, S.D. Dover, Journal of Microscopy, 126 (1982) 211-213. 
[21] L. Salvo, M. Suéry, A. Marmottant, N. Limodin, D. Bernard, Comptes Rendus Physique, 11 (2010) 641-649.

[22] A. Stiénon, A. Fazekas, J.Y. Buffière, A. Vincent, P. Daguier, F. Merchi, Materials Science and Engineering: A, 513-514 (2009) 376-383.

[23] T.O. Mbuya, I. Sinclair, A. Moffat, P. Reed, Int. J. Fatigue, 42 (2012) 227-237.

[24] P. Li, P.D. Lee, T.C. Lindley, D.M. Maijer, G.R. Davis, J.C. Elliott, Advanced Engineering Materials, 8 (2006) 476-479.

[25] W. Ludwig, J.Y. Buffière, S. Savelli, P. Cloetens, Acta Mater., 51 (2003) 585-598.

[26] E. Ferrié, J.Y. Buffière, W. Ludwig, Int. J. Fatigue, 27 (2005) 1215-1220.

[27] T.J. Marrow, J.Y. Buffiere, P.J. Withers, G. Johnson, D. Engelberg, Int. J. Fatigue, 26 (2004) 717725.

[28] H. Toda, Microscopy (Oxford, England), 63 Suppl 1 (2014) i3-i4.

[29] S. Birosca, J.Y. Buffiere, F.A. Garcia-Pastor, M. Karadge, L. Babout, M. Preuss, Acta Mater., 57 (2009) 5834-5847.

[30] M. Herbig, A. King, P. Reischig, H. Proudhon, E.M. Lauridsen, J. Marrow, J.-Y. Buffière, W. Ludwig, Acta Mater., 59 (2011) 590-601.

[31] K.A. Soady, B.G. Mellor, J. Shackleton, A. Morris, P.A.S. Reed, Materials Science and Engineering a-Structural Materials Properties Microstructure and Processing, 528 (2011) 8579-8588.

[32] E.R. De los Rios, A. Walley, M.T. Milan, G. Hammersley, Int. J. Fatigue, 17 (1995) 493-499.

[33] S. Curtis, E.R. de los Rios, C.A. Rodopoulos, A. Levers, Int. J. Fatigue, 25 (2003) 59-66.

[34] K.A. Soady, B.G. Mellor, G.D. West, G. Harrison, A. Morris, P.A.S. Reed, Int. J. Fatigue, 54 (2013) 106-117.

[35] B.Y.He, K.A. Soady, B.G. Mellor, P.A.S. Reed, accepted by Internation Journal of Fatigue, (2014).

[36] B.Y. He, K.A. Soady, B.G. Mellor, A. Morris, P.A.S. Reed, Materials Science and Technology, 29 (2013) 788-796.

[37] T. Fujita, Isij International, 32 (1992) 175-181.

[38] J.Y. Buffiere, E. Ferrie, H. Proudhon, W. Ludwig, Materials Science and Technology, 22 (2006) 1019-1024.

[39] P.M. Scott, T.W. Thorpe, Fatigue \& Fracture of Engineering Materials \& Structures, 4 (1981) 291309.

[40] Y. Mutoh, I. Sakamoto, in: S.R. Valluri, D.M.R. Taplin, P.R. Rao, J.F. Knott, R. Dubey (Eds.) Proceedings of the 6th International Conference on Fracture (ICF6), Pergamon, New Delhi, India, 1984.

[41] J. Lankford, F.N. Kusenberger, MT, 4 (1973) 553-559.

[42] K. Tanaka, T. Mura, MTA, 13 (1982) 117-123.

[43] in: British Standard, BS EN ISO 6507-1:2005:Metallic materials - Vickers hardness test - Part 1: Test method, 2005.

[44] R. Steiner, ASM Handbook Volume 1: Properties and Selection: Irons, Steels, and HighPerformance Alloys, 1990. 